\title{
Market Makers' Optimal Price-Setting Policy for Exchange-Traded Certificates
}

\author{
Stefanie Baller* \\ University of Passau \\ Oliver Entrop ${ }^{\dagger}$ \\ University of Passau \\ Marco Wilkens ${ }^{\ddagger}$ \\ University of Augsburg
}

Working Paper

January 2014

*Stefanie Baller, University of Passau, Chair of Finance and Banking, Innstraße 27, D-94032 Passau, Germany, phone: +49 851509 2463, email: stefanie.baller@uni-passau.de

${ }^{\dagger}$ Oliver Entrop, University of Passau, Chair of Finance and Banking, Innstraße 27, D-94032 Passau, Germany, phone: +49851509 2460, email: oliver.entrop@uni-passau.de

${ }^{\ddagger}$ Marco Wilkens, University of Augsburg, Chair of Finance and Banking, Universitätsstraße 16, D-86159 Augsburg, Germany, phone: +49 821598 4124, email: marco.wilkens@wiwi.uni-augsburg.de 


\title{
Market Makers' Optimal Price-Setting Policy for Exchange-Traded Certificates
}

\begin{abstract}
This paper considers the pricing of certificates on exchanges for retail investors. The contribution to the literature is twofold: (i) We provide the first theoretical model that analyzes the optimal, i.e. profit-maximizing price-setting policy of the issuer over a certificate's life time. Our model derives and examines the nexus between optimal markup and optimal spread inter-temporally set by the issuer, unhedgeable risk faced by the issuer, and investors' buying and selling decisions. (ii) Analyzing the German market for leverage certificates, we provide the first comprehensive empirical analysis of model-derived hypotheses on the issuers' pricing policies that accounts for possible endogeneity between markup and spread and concretizes the effects of unhedgeable risk, volume and order flow.
\end{abstract}

Keywords: Structured Financial Products; Leverage Certificates; Pricing Behavior; Monopoly Pricing Model

JEL classification: D40, G13, G24 


\section{Introduction}

The value of certificates, i.e. structured financial retail products, globally under management is comparable in size to the hedge fund industry (Lord, 2011). There is a large body of empirical work analyzing the price quality for these certificates on retail investors exchanges. Wilkens et al. (2003) are the first to find overpricing in the German market - one of worldwide largest of its kind-which has been confirmed by many subsequent studies. Analogue findings are, e.g., reported by Henderson and Pearson (2011) for the US and by Hernández et al. (2013) for a European sample. ${ }^{1}$ Empirically there is evidence that issuers decrease overpricing over the certificate's life time (e.g., Stoimenov and Wilkens, 2005; Baule et al., 2008; Baule, 2011) which is commonly subsumed under "life cycle hypothesis", incorporate higher markups in more complex products (e.g., Stoimenov and Wilkens, 2005; Wilkens and Stoimenov, 2007), increase markups at the end of the day (Entrop et al., 2013b), decrease markups when competition is higher (Baule, 2011) and anticipate investors' systematic trading patterns and adjust markups accordingly (Baule, 2011), which is consistent with the "order flow hypothesis" (Wilkens et al., 2003).

Recent empirical findings suggest that individual investors act uninformed in this market (Meyer et al., 2013; Schroff et al., 2013) and that the issuers' pricing policy is - besides standard behavioral biases - the key reason for investors' negative returns in short-term certificates (Entrop et al., 2012) and poor risk-adjusted performance in long-term certificates (Entrop et al., 2013a). In fact, theoretical models imply that investors' demand for certificates can hardly be justified by standard preferences (Breuer and Perst, 2007; Branger and Breuer, 2008; Bernard

\footnotetext{
${ }^{1}$ Other studies reporting overpricing include for the US Chen and Kensinger (1990); Chen and Sears (1990); Baubonis et al. (1993); Benet et al. (2006), for Germany Stoimenov and Wilkens (2005); Muck (2006); Wilkens and Stoimenov (2007); Baule et al. (2008); Baule (2011); Baule and Tallau (2011), for Switzerland Wasserfallen and Schenk (1996); Burth et al. (2001); Grünbichler and Wohlwend (2005); Wallmeier and Diethelm (2009), and for the Netherlands Szymanowska et al. (2009).
} 
et al., 2009).

We contribute to this literature by providing the first theoretical model on the optimal pricesetting policy of the issuers deriving the linkage between optimal markup and optimal spread inter-temporally set by the issuer, unhedgeable risk faced by the issuer, and investors' buying and selling decisions. By doing so, we aim at closing a conspicuous gap in the present literature on certificates. In fact we find a theoretical explanation of the well-known life cycle and the order flow hypotheses, but are also able to identify additional patterns in the issuers' price-setting: The (intra-day) structure of the optimal price-setting is foremost affected by the unhedgeable risk faced by the issuer, the (intra-day) order flow and also the fraction of investors that hold the product beyond the unhedgeable risk event. In our model the spread is no longer constant but also an endogenous variable, which interacts negatively with the markups. We separate the spread effect into a pure spread effect, where the issuer does not need high markups because the spread is already large enough for a given amount of profit and a more important signal effect, where the spread is the visible signal for the price quality in the market.

Additionally, we add to the empirical literature by running the first comprehensive empirical analysis that not just focuses on a single aspect but jointly tests model-derived hypotheses. For a data set on retail leverage certificates we find clear empirical evidence for the life cycle hypothesis. Concerning the order flow we find evidence that the issuer adjusts his pricingbehavior with respect to the ratio of extraordinary sell and buy orders. Thus issuers distinguish between the buy and the sell side according to their pricing policy. Moreover, we find that the unhedgeable risk's influence on the markup increases with the proximity of the overnight gap. The overall jump risk has a decreasing effect on the premiums for short and an increasing effect on the premiums for long certificates. Confronted to the theoretical model, the spread effect on the premiums is positive which leads to the conclusion that demand sensitivity towards the 
spread is indeed significantly larger than the demand sensitivity towards the markups.

The paper proceeds as follows. In Section 2 we provide our model and derive the corresponding hypotheses. Section 3 contains the empirical analysis, where Section 3.1 and 3.2 give an overview over the market of leverage certificates, our data set and the valuation procedure. In Section 3.3 and 3.4 we show the empirical results and check hypotheses of the model. Section 4 concludes.

\section{Market design and model}

\subsection{Market design}

We focus on the German market as it is one of the world's largest in the segment of retail products. Structured retail products can either be traded on exchanges or directly on the issuers' own trading platforms. Major German exchanges are the EUWAX and Scoach in Stuttgart and Frankfurt, respectively. ${ }^{2}$ The market structure of the respective exchange has a key influence on the price formation. Exchange traded retail certificates are traded via a continuous auction, where orders are booked and executed when they arrive.

Issuers are obliged to serve as market makers and quote binding bid and ask prices for their certificates. The market is therefore quote-driven and the market maker takes the opposite side of every transaction. ${ }^{3}$ This specific market design ensures high liquidity of the products. In combination with explicitly forbidden short-selling investors cannot arbitrage a probable overpricing. Hence it is easy for issuers to extract economic rents only limited by the competition between issuers of substitute products. Identifying substitute products in this market sector is

\footnotetext{
${ }^{2}$ Most of the following comments is also applicable to other European exchanges, as the Swiss Scoach, IDEM of Borsa italiana, London Stock Exchange Securitised Derivatives and Nordic Derivatives Exchange. All of them base on a similar market maker system, which guarantees liquidity in the market.

${ }^{3}$ In reality orders can be executed within the bid-ask spread when the market maker can match buy and sell orders of investors. However, due to the limited number of trades in each single product, this does not happen often. Therefore, we neglect this in the following.
} 
challenging for retail investors due to a large variety of product names and product features (see Entrop et al., 2013a, for recent empirical evidence). ${ }^{4}$ Moreover, it is often argued that it is hard for individual investors - due to limited financial literacy, especially in the case of very complex certificates - to assess the "fairness" of quoted prices as this would require to calculate fair market values. However, investors' do have a certain price sensitivity that limits the complete freedom of the issuers' price-setting power (Baule, 2011; Baule and Blonski, 2013). ${ }^{5}$

At last, this price-setting power is further enhanced by the fact that a bought product can only be traded with its issuer. This characteristic is the primal reason why using common market microstructure models would be misleading in our context.

Moreover, often considered market frictions such as inventory costs (e.g., Garman, 1976; Stoll, 1978; Ho and Stoll, 1981, 1983; Hasbrouck and Sofianos, 1993) or informed traders (e.g., Glosten and Milgrom, 1985; Kyle, 1985) are of minor importance. The reason for the first is that market makers do not have to balance demand and supply as they can satisfy any demand quantity because they issue the product themselves and simply "close" the certificate when it is sold back. The reason for the latter is that most investors in this market segment are uninformed (Meyer et al., 2013; Schroff et al., 2013). Even if an investor was informed, the resulting risk for the market maker is negligible as he hedges the certificate when an order arrives. Therefore, an investor's ability to predict the market will not cause a loss in the market makers' portfolio. The scope of the spread also contrasts the market microstructure literature fundamentally, where the spread represents liquidity in the market and is supposed to be smaller in highly liquid markets (Huang and Stoll, 1996). However, in our model setup the spread serves as a signal for the market's price quality.

\footnotetext{
${ }^{4}$ For example, as of November 2013 there were 1,127,838 certificates listed and 188,755 newly issued on EUWAX at the same time.

${ }^{5}$ Dorn (2012) in contrast finds that investors do not compare prices but rely on suboptimal choice heuristics even if the environment is transparent.
} 


\subsection{General model setup}

We analyze the behavior of a single market maker (= issuer) for a specific certificate, where the market is modeled as a discretized, inter-temporally structured continuous auction, i.e. orders are booked and executed at the quoted prices set by the issuer immediately when they arrive. ${ }^{6}$ The issuer is the only possible trading opponent for the investors in the considered certificate.

We focus on a finite time period, which consists of 4 discrete points in time $t_{i}=i, i=0,1,2,3$. The product is issued in $t_{0}$ and becomes due in $t_{3}$. At issuance, the issuer sets an ask price $p_{0}^{A}$ that equals the fair value $p_{0}$ plus an ask markup $\alpha_{0} \cdot{ }^{7}$ At maturity, he sets a bid price that equals the fair value, i.e. the pay-off of the certificate. During the life time of the certificate the issuer is willing to sell and rebuy certificate units at ask and bid prices $p_{i}^{B}$ and $p_{i}^{A}$ that equal the fair value $p_{i}$ in $t_{i}$ plus ask and bid markups $\alpha_{i}$ and $\alpha_{i}-v$, respectively, where $v$ denotes the bid-ask spread. The inter-temporal price structure is thus given by:

$$
\begin{array}{ll}
p_{i}^{A}=p_{i}+\alpha_{i}, \quad p_{i}^{B}=p_{i}+\alpha_{i}-v & \text { for } i=0,1,2, \\
p_{3}^{B}=p_{3} . &
\end{array}
$$

It should be noted that the fair price in our model does not have to be between the bid and ask quotes but can rather be above or below both of them. However, we require the spread to be non-negative, i.e. $v \geq 0$.

Once the product is purchased by the investor, the issuer immediately hedges the outstanding position at the fair value $p_{i}$. If the product is sold back, the issuer unwinds his hedge position at the respective fair value at that point in time. However, the issuer may be exposed to some

\footnotetext{
${ }^{6}$ The base structure of our model is similar to inter-temporal monopoly models and models from the field of durable goods such as Coase (1972), Stokey (1981), Bulow (1982) and Desai and Purohit (1998).

${ }^{7}$ For time consistency, we also assume that the issuer sets a bid price like in the subsequent periods.
} 
unhedgeable risk. To isolate the effect of unhedgeable risk in the following, we assume that it only exists when the product is held by the investor between $t_{2}$ and $t_{3}$. This is included in the model via opportunity costs $g$ the issuer has to bear when he unwinds the hedge position in $t_{3}{ }^{8}$

Investors' selling decisions are independent and poisson distributed which is a common assumption (Garman, 1976). Due to the independence assumption, the poisson parameter transforms, for each point in time and when a large number of investors is considered, into a fixed fraction of the product demand that is sold back by the investors. To reduce the number of parameters in the following, we allow the certificates bought by the investors in $t_{0}$ not to be given back in $t_{2}$. This implies that a fraction $\gamma_{1}$ of those certificates bought in $t_{0}$ is given back in $t_{1}$ and the remaining fraction $1-\gamma_{1}$ is held until maturity. Analogously, fractions $\gamma_{2}$ and $1-\gamma_{2}$ from those certificates bought in $t_{1}$ are given back in $t_{2}$ and $t_{3}$, respectively, while, of course, all certificates bought in $t_{2}$ are sold back at maturity $t_{3}$. Figure 1 illustrates the model structure and the resulting cash flows.

[Figure 1 about here.]

Given the demand $D_{i}$ in $t_{i}$ the corresponding profit function $\pi_{i}$ of the market maker-from certificates sold in $t_{i}$-is the sum of the cash flows from the selling and rebuying certificates (certificates portfolio) over time minus the cash flows from the related hedge positions (hedge portfolio):

$$
\pi_{i}=\underbrace{\left[p_{i}^{A}-\gamma_{i+1} p_{i+1}^{B}-\left(1-\gamma_{i+1}\right) p_{3}\right] D_{i}}_{\text {certificates portfolio }}-\underbrace{\left[p_{i}-\gamma_{i+1} p_{i+1}-\left(1-\gamma_{i+1}\right)\left(p_{3}-g\right)\right] D_{i}}_{\text {hedge portfolio }} \text { for } i=0,1,2
$$

\footnotetext{
${ }^{8}$ Liquidity squeezes or jump events in the underlying might cause such an unhedgeable risk situation, where the issuer is not able to shift the resulting losses in his hedge position upon the investor. For taking and closing the hedge position we neglect transaction costs in the following.
} 
where we set $\gamma_{3}=0$ for consistency, and time discount factors are neglected. Substituting (1) and (2) into (3), collecting and rearranging terms, and summing up the 3 profit functions gives the aggregated profit function $\pi_{a g g}=\pi_{1}+\pi_{2}+\pi_{3}$ of the market maker over the product's life time:

$$
\pi_{\text {agg }}=\left(\alpha_{0}-\gamma_{1}\left(\alpha_{1}-v\right)-\left(1-\gamma_{1}\right) g\right) D_{0}+\left(\alpha_{1}-\gamma_{2}\left(\alpha_{2}-v\right)-\left(1-\gamma_{2}\right) g\right) D_{1}+\left(\alpha_{2}-g\right) D_{2} .
$$

The next step is to specify the aggregated market demand functions $D_{i}$. We assume a timeindependent base demand $x$ with $D_{i}^{\prime}(x)>0$. As there is empirical evidence that demand is not constant over time but can depend on the remaining time to maturity of a certificate (Baule, 2011) or the time of day (Entrop et al., 2013b) we allow for demand shifts $w_{i}$ in $t_{1}$ and $t_{2}$ with $D_{i}^{\prime}\left(w_{i}\right)>0$

Additionally, the demand depends negatively on the "unfairness" of the ask quotes represented by the ask markups, i.e. $D_{i}^{\prime}\left(\alpha_{i}\right)<0$. The empirical evidence on the investors' sensitivity towards the overpricing has already been discussed in Chapter 2.1. Finally, the demand also depends negatively on the spread $v$, i.e. $D_{i}^{\prime}(v)<0$. In contrast to the markup, the spread is directly observable by the investor who is assumed to prefer a smaller spread. Here the issuer faces a trade-off: the higher the markup and also the spread the higher his profit but the smaller the demand, which again leads to a negative impact on the profit.

Due to the investors' ability to observe the spread directly, the sensitivity with respect to the spread has to be larger than the sensitivity with respect to the ask markup.

To obtain analytical solutions in the subsequent analysis, we consider the following demand 
functions that fulfill the above requirements:

$$
D_{i}=x+w_{i}-y \alpha_{i}-z v^{2}, \quad \text { for } i=0,1,2,
$$

where $x, y, z \geq 0$ and $w_{i}$ are constants with $w_{0}=0 . y$ and $z$ represent the demand sensitivities towards the markup and the spread. We consider the squared spread $v^{2}$ for technical reasons as using the simple spread $v$ could set incentives for a negative optimal spread in the following optimization procedure. Given $v \geq 0$ this would result in a corner solution, which we find unrealistic from an economic point of view.

The market maker knows the aggregated demand functions and acts as a profit maximizer when setting the ask markups and the spread. Thus, the market maker's optimization problem reads:

$$
\max _{\alpha_{0}, \alpha_{1}, \alpha_{2}, v} \pi_{a g g} \quad \text { s.t. } \quad D_{i} \geq 0, v \geq 0 .
$$

\subsection{Model solution}

Optimizing the above aggregated profit function (6) gives the optimal ask markups and the optimal spread. For major special cases this can be done analytically, otherwise numerical solutions are obtained straightforwardly. We first analyze the problems when all certificates are held until maturity (Section 2.3.1) and all certificates are sold back in the subsequent point in time after the buy (Section 2.3.2). The results in the general case (Section 2.3.3) are then basically a mixture of the results of these special cases. 


\subsubsection{Special case 1: Holding until maturity}

In this first special case, all investors hold the product until maturity, which means $\gamma_{1}, \gamma_{2}=0$. Thus, the aggregated profit function (4) simplifies to:

$$
\pi_{\text {agg }}=\left(\alpha_{0}-g\right) D_{0}+\left(\alpha_{1}-g\right) D_{1}+\left(\alpha_{2}-g\right) D_{2} .
$$

We optimize this profit function with respect to the ask markups and the spread. The necessary and sufficient conditions are shown in Appendix A. The optimal spread in this case becomes zero, because the product is never given back at the bid price before maturity, but a positive spread would decrease the demand. The optimal ask markups are given by:

$$
\begin{array}{lll}
\alpha_{0}^{*}=\frac{x}{2 y} & +\frac{g}{2}, \\
\alpha_{1}^{*}=\frac{x}{2 y} \quad+\frac{w_{1}}{2 y} \quad+\frac{g}{2}, \\
\alpha_{2}^{*}=\underbrace{\frac{x}{2 y}}_{1)} \underbrace{+\frac{w_{2}}{2 y}}_{2)} \underbrace{+\frac{g}{2}}_{3)} .
\end{array}
$$

The three optimal markups have the same structure with two or three components, that we analyze in the following.

1) A higher level of base demand $x$ increases the ask markups. Additionally, the sensitivity $y$ of the demand towards the markup level diminishes the markup. The reason is obvious: Demand decreases if the investors react more sensitive to the markup level, this higher sensitivity is compensated by smaller markups to achieve a higher demand.

2) The ask markups only differ with respect to the demand shifting parameters $w_{i}$. A demand shock in $t_{1}$ or $t_{2}$ affects the markup at once. For a positive $w_{i}$ issuers exploit the extra demand by setting higher markups while the opposite holds for negative demand shifts. 
3) The unhedgeable risk in form of the opportunity costs $g$ has also an increasing effect on the markups. As all certificates are held until maturity the issuer is exposed to the unhedgeable risk, independent of the point in time when the certificate has been bought. Thus, the issuer inserts his opportunity costs into all markups equally and passes them to the investor.

\subsubsection{Special case 2: Selling back at the next point in time}

If the return fractions $\gamma_{1}, \gamma_{2}$ are equal to unity, the product is sold back immediately in the following point in time to the purchase. The profit function (4) becomes:

$$
\pi_{a g g}=\alpha_{0} D_{0}-\left(\alpha_{1}-v\right) D_{0}+\alpha_{1} D_{1}-\left(\alpha_{2}-v\right) D_{1}+\alpha_{2} D_{2}-g D_{2}
$$

The necessary and sufficient conditions of the optimization problem are shown in Appendix B resulting in the following optimal ask markups and the optimal spread $v^{*}$. The optimal markups shown do also depend upon the optimal spread. Momentarily we neglect the indirect effects of the exogenous parameters on the markups via the spread and interpret the spread as exogenous. ${ }^{9}$ As the direct effects dominate the indirect, which will be discussed later, we find this procedure to be better interpretable. The optimal markups read:

$$
\begin{aligned}
& \alpha_{0}^{*}=\frac{3 x}{4 y}+\frac{w_{1}+w_{2}}{4 y} \quad+\frac{g}{4} \quad-\frac{5 v^{*} y+3 v^{* 2} z}{4 y}, \\
& \alpha_{1}^{*}=\frac{2 x}{4 y} \quad+\frac{2 w_{1}+2 w_{2}}{4 y}+\frac{2 g}{4} \quad-\frac{6 v^{*} y+2 v^{* 2} z}{4 y}, \\
& \alpha_{2}^{*}=\underbrace{\frac{x}{4 y}}_{1)} \underbrace{+\frac{-w_{1}+3 w_{2}}{4 y}}_{2)}+\underbrace{+\frac{3 g}{4}}_{3)} \underbrace{-\frac{3 v^{*} y+v^{* 2} z}{4 y} .}_{4)}
\end{aligned}
$$

\footnotetext{
${ }^{9}$ If the spread was really exogenous and not to be optimized, the optimal markups would be identical.
} 
In contrast to solution (8) of special case 1 from Section 2.3.1, the optimal markups contain a fourth component dominated by the spread. Interestingly - again in contrast to the previous special case - each component has a specific inter-temporal structure, i.e. it varies depending upon the point in time considered.

1) Like in the previous case, the ask markups increase (decrease) with the base demand $x$ (markup demand sensitivity $y$ ). However, over time, i.e. from $t_{0}$ to $t_{2}$, the respective component decreases, which also leads to decreasing markups ceteris paribus. Decreasing markups are a well-reported phenomenon in the related empirical literature and commonly subsumed under "life cycle hypothesis" (e.g., Stoimenov and Wilkens, 2005). Technically, the markups have to decrease because issuers would only earn the spread if the markups were constant; on the other hand, if the markups would be set to zero already in $t_{1}$ and $t_{2}$, this would result in a high profit from those certificates bought in $t_{0}$ but, again, issuers would earn only the spread from those certificates bought in $t_{1}$ and $t_{2}$. Hence, our model implies that it is optimal for the issuer to melt off the markups over the life cycle of the product to earn his rents throughout the whole life time which is consistent with the literature.

Hypothesis 1 (Life cycle hypothesis). The markups decrease over the product's life time.

2) Again like in the previous case, positive (negative) extraordinary demand movements $w_{i}$ have a positive (negative) influence on the ask markups at once when the shock occurs. However, demand shifts also affect the markups at other points in time. Let us for example assume $w_{1}>0$ and $w_{2}=0$. Then the issuer would significantly increase the ask markup in $t_{1}$ and additionally lower the ask markup in $t_{2}$. This allows him to exploit best the extraordinary demand in $t_{1}$ as it is given back in $t_{2}$ at the difference between the ask 
markup and the spread. Of course, due to the lower markup in $t_{2}$, the profit resulting from the amount bought in $t_{2}$ is also reduced. Obviously, the issuer faces a significant trade-off problem, because alternatively to the solution above, the issuer could also increase the spread. However, this would be suboptimal in our setting as a constant spread decreases the demand at any point in time.

The issuer faces also a second trade-off problem: He could already increase the markup in $t_{0}$. This is at first glance not optimal for the issuer due to a resulting decreasing demand at this point in time. However, he accepts this loss in demand, because otherwise he would have an even bigger loss due to the increased markup in $t_{1}$ at which the amount bought in $t_{0}$ is given back. Analogue considerations hold for $w_{2}$.

All in all, the issuer increases (decreases) the markup at and before (after) the event of the extraordinary demand shift. The farer away the period from the demand shift event, the less the markup is influenced by this shift. Such adjustments of the pricing policy to the anticipated demand are basically consistent with the "order flow hypothesis" (e.g., Wilkens et al., 2003) that has been proven empirically - due to data limitations - only by Baule and Tallau (2011) and by Entrop et al. (2013b). Our model provides a detailed structure of the extraordinary demand effect:

Hypothesis 2 (Order flow hypothesis). The market maker adjusts his markups with respect to the order flow. A positive (negative) demand shift results in an increase (decrease) of the ask markups in the same period and-to a less extent-the periods before. On the subsequent markups the effect is negative (positive).

3) Again like in the previous case, the opportunity costs $g$ of the unhedgeable risk are included in all three markups, i.e. the issuer passes this costs on to the investors. It is worth 
emphasizing that the opportunity costs have also an influence on the markups in $t_{0}$ and $t_{1}$, although the product is given back before the unhedgeable risk becomes important for the issuer. Hence, investors who bought the product in $t_{0}$ or $t_{1}$ have to pay for the unhedgeable risk even if they do not expose the issuer to it. It seems to be optimal for the issuer to spread the opportunity costs across all investors. The alternative, i.e. increasing the ask markup in $t_{2}$ is suboptimal in our setting. This would significantly increase the bid price in $t_{2}$ as well, which would decrease the profit from the certificates bought in $t_{1}$. However, the opportunity costs are charged at a higher level with increasing proximity of the unhedgeable risk event and the point in time when the certificate is bought.

Hypothesis 3 (Unhedgeable risk hypothesis). The unhedgeable risk $g$ increases the markups. This effect is more pronounced the closer the buying time is to the unhedgeable risk event.

4) The overall effect of the spread on the markups is negative due to its contribution on the issuers profit. However, the spread effect can be divided into two subeffects: First, the spread directly influences the price-setting structure of the issuer. If the spread is high, the profit of the issuer is increased already due to this high spread. Therefore the ask markup must not be set at such a high level and the spread has a negative effect on the ask markups ("pure spread part") . On the other hand, it exists a negative influence of the spread on the demand function. The investor will buy less, the worse the spread signal appears ("spread signal part"). If the spread is enlarged, the ask markup is decreased straight away to stabilize the demand. This part is the reason for the dealer not to set the spread as broad as possible, which would be the case otherwise.

Hypothesis 4 (Spread hypothesis). The spread and the markups are negatively related. 
As in the former special case, the demand sensitivity to the markup $y$ has a diminishing effect on the ask markup, assuming that the demand is positive. This holds also for the demand sensitivity towards the spread $z$. A smaller ask markup for a larger $z$ is a compensation for the negative impact of $z$ on the demand function.

The optimal spread $v^{*}$ in this special case is given by:

$$
v^{*}=\frac{y}{2 z}+\frac{1}{2}\left(A-\sqrt{A^{2}-B^{3}}\right)^{\frac{1}{3}}+\frac{B}{2\left(A-\sqrt{A^{2}-B^{3}}\right)^{\frac{1}{3}}}
$$

where

$$
\begin{aligned}
& A=\frac{y^{3}}{8 z^{3}}-\frac{3 x y+w_{1} y-3 w_{2} y-3 g y^{2}}{12 z^{2}}+\frac{6 x y z+2 w_{1} y z+2 w_{2} y z-6 g z y^{2}-11 y^{3}}{24 z^{3}}, \\
& B=\frac{y^{2}}{4 z^{2}}+\frac{6 x z+2 w_{1} z+2 w_{2} z-6 g z y-11 y^{2}}{18 z^{2}} .
\end{aligned}
$$

The optimal spread is mainly determined by the variables $g, x$ (and $w_{i}$ ) and the sensitivities $y$ and $z$. Obviously, it converges to zero for a large spread sensitivity $z$. This is natural asfor a given spread - a higher $z$ reduces the demand and, thus, the issuer's profit. Therefore, the spread is reduced to stabilize demand. ${ }^{10}$ Due to the complexity of the function, we show comparative statics of these four variables in Figure 2 where parameters are set at realistic values from economic point of view. As for the range of the variables it must be assured that the demand at the fair value $x$ is at a sufficiently high level to guarantee a positive demand. Therefore $x$ is held fix and only the demand shocks $w_{i}$ are varied. Also due to the positive demand constraint, the opportunity costs of the unhedgeable risk $g$ and the sensitivity $y$ must

\footnotetext{
${ }^{10}$ Additionally, it is straightforward to show that the derivatives of $v^{*}$ with respect to the parameters $x, g$, etc. become arbitrarily close to zero for sufficiently large $z$. For that reason the direct effects of these parameters on the optimal markups via the components 1) to 3) in (10) dominate the indirect effects via the spread.
} 
be sufficiently small. Moreover it is reasonable that the ratio $\frac{z}{y}$ is larger than unity. The reason is that in contrast to the ask markup level the spread can be observed directly by the investor. Therefore the investor should react more sensitive to the spread than to the ask markup level.

[Figure 2 about here.]

The spread is an increasing function of the unhedgeable risk $g$. If the issuer faces increasing unhedgeable risk, the spread is widened, which is a protection effect of the issuer and the bid markup is set smaller with respect to the ask markup. The spread decreases with higher positive demand shocks in $t_{2}$ and decreases only modestly with a higher positive demand shock in $t_{1}$. A positive demand shock in $t_{1}$ increases the demand in $t_{1}$ and more is bought. But the dealer has to consider that there is a subsequent period where also a higher amount has to be given back. These effects even out nearly completely. If a positive demand shock occurs in $t_{2}$ the dealer has not to consider how much of the product is sold back. Hence the spread is decreased to sell a higher amount of the product. The effects of negative demand shocks are vice versa.

$z$ has an overall negative impact on the spread. If the demand sensitivity towards the spread is high, this has a negative influence on the demand. To offset this effect up to a certain level, the spread is decreased. If $y$ is high the spread is increased. Hence the issuer has to compensate the higher demand sensitivity to the ask markup level and the parallel lower level of ask markups by an increase in the spread.

\subsubsection{Complete Model}

Even if a large number of leverage certificates is purchased and sold back within one trading day, the most realistic scenario from above are certainly return fractions between 0 and 1 . Therefore it is helpful for the following analysis to show that the analytic solutions are only special cases of the general model. For convenience we assume that $w_{i}=0$ and $\gamma_{1}=\gamma_{2}$ and 
maximize numerically the general model with respect to the spread and the ask markups for varying return fractions from zero to one. ${ }^{11}$ The results in Figure 3 show that the markups of the general model are indeed a combination of the two extreme cases, where the investor gives back the product immediately or at the end of the planning horizon.

\section{[Figure 3 about here.]}

If demand shocks do not exist the model markups, also for return fractions between zero and one, are consistent with the life cycle hypothesis, i.e. the ask markups decrease over time. Some conditions, as also mentioned in Chapter 2.3.2, can reverse or at least weaken this relationship. Positive demand shifts in $t_{1}$ and $t_{2}$, which are a characteristic of the intra-day order flow, can reverse the life cycle hypothesis in combination with a higher impact of the unhedgeable risk (view Figure 4).

[Figure 4 about here.]

This holds only for small levels of return fractions, because a larger fraction of the product is held until maturity where the opportunity costs have a larger impact on the issuers profit.

\section{Empirical Analysis}

\subsection{Leverage certificates}

For our empirical analysis we focus on the market of so-called leverage certificates. Compared to normal warrants, leverage certificates contain a knock-out feature. If the underlying touches the predefined knock-out barrier $B$ the product knocks out immediately and becomes worthless. ${ }^{12}$

In comparison to other retail products, leverage certificates have two major advantages for our analysis: First, the holding period of leverage certificates is rather short (Entrop et al.,

\footnotetext{
${ }^{11}$ The necessary and sufficient conditions for a maximum if $0<\gamma_{1}=\gamma_{2}<1$ are shown in Appendix C.

${ }^{12}$ Normally there is a repayment of EUR 0.01, which is tax-driven. We neglect this in the following.
} 
2013b). Therefore one product is traded more often compared to warrants or similar investment products. A certain trading frequency is essential to execute a valid analysis of order flow effects. Second, the already mentioned knock-out characteristic makes these leverage certificates preferable to products without such a feature for our purpose: The common hedging approach of these products is a semi-static superhedge via futures or forwards. Normally the issuer closes his position immediately if the knock-out barrier is touched. If, due to jumps of the underlying, the barrier is under(over)shot, the hedge becomes negative. The issuer has to bear this unhedgeable risk, called gap risk, by himself. ${ }^{13}$ Particularly in the context of knock-out products the occurrence of this risk can be temporarily isolated and identified very well in the form of the overnight gap risk. In most cases the underlying jumps over night, hence for products traded close to the over night gap, the unhedgeable risk might be of major importance and the issuers might charge higher premiums.

We concentrate on leverage certificates with finite maturity and a strike identical to the barrier. Two types of leverage certificates exist: Long leverage certificates and short leverage certificates. Long leverage certificates are basically equivalent to down-and-out calls, where the investor profits from increasing values of the underlying. Short leverage certificates are equivalent to up-and-out puts. Here the investor profits from a decrease in the underlying level.

The pay-off at maturity is equal to the pay-off of a traditional warrant. Only during the life time the knock-out can take place at any moment, when the underlying hits the barrier.

\footnotetext{
${ }^{13}$ For more detail see Entrop et al. (2013b); Carr et al. (1998); Mahayni and Suchanecki (2006).
} 
Formalized the value of short and long leverage certificates reads:

$$
\begin{aligned}
\text { long leverage certificate: } \quad L C_{T}^{\text {long }} & =c \max \left(S_{T}-X, 0\right) 1_{\left\{\tau^{\text {long }}>T\right\}} \\
\text { with } \quad \tau^{\text {long }} & =\inf \left\{t>0: S_{t} \leq X\right\}, \\
\text { short leverage certificate: } \quad L C_{T}^{\text {short }} & =c \max \left(X-S_{T}, 0\right) 1_{\left\{\tau^{\text {short }}>T\right\}} \\
\text { with } \quad \tau^{\text {short }} & =\inf \left\{t>0: X \leq S_{t}\right\},
\end{aligned}
$$

where $1_{\{\cdot\}}$ is the indicator function. It is 1 if the barrier was not hit during the life time of the product and zero otherwise. $\tau$ is the first passage time, i.e. the time when the barrier is hit by the underlying for the first time during the product's life time. $c$ is the conversion ratio. ${ }^{14}$

\subsection{Dataset and Valuation}

\subsubsection{Dataset}

We use a combination of data sets for the second quarter of 2009 till the third quarter of 2011 which contain intra-day base and quote data of leverage certificates on the German blue chip index DAX that are listed on the EUWAX. ${ }^{15}$ We retrieve quote data on an hourly frequency basis from 10 a.m. onwards. Furthermore we co-opt some additional points in time of particular relevance: As time for the first quote we use 9:30 a.m., where first market movements can be guaranteed and as time for the last quote we use 7:50 p.m., hence the market is still open but about to close in the following minutes. In between we additionally choose 5:30 p.m. and 7:30 p.m. At 5:30 p.m. the underlying market closes, which leads to intensified agitation in the market, and at 7:30 p.m., short before the product market closes, we also find it reasonable to

\footnotetext{
${ }^{14} c$ is usually 0.01 and scales the value of the certificate to a consumer-friendly level.

${ }^{15}$ The base data on issued certificates were kindly provided to us by the financial data provider Deriva GmbH Financial IT and Consulting. The quote data were sourced from the SIRCA Thomson Reuters Tick History (TRTH).
} 
use a smaller time interval.

The third part of the data set comprises transaction data of the products directly provided by the EUWAX ${ }^{16}$, i.e. time, price, volume and a buy/sell-flag of the trade. Furthermore we know whether the order is a limit, a market or an other order type (stop-loss, stop-buy or exotic $^{17}$ ) and the respective limit price if applicable. Whereas other data sources only report aggregated volume data, this transaction data enables us to identify the direction of trade, i.e. if it is a sell or a buy, which is a key information for the order flow analysis. The transaction data is aggregated up to the same frequency of the quote data separately for each order type. For example the aggregated sell volume for limit orders at 4:00 p.m. is the sum of all sell limit order volumes in the time period from 3:00 p.m. till 4:00 p.m.

On the EUWAX a broad variety products is issued per day and issuer for various times to maturity and strikes. The number of products in our original data set is 71,338 . The majority, exactly nearly $78 \%$ of these products, remain untraded during their whole life time. Untraded products are highly liable to stale prices and non-rational pricing of the issuer, because they simply do not have to adjust the markups with respect to market movements. We eliminate those products and concentrate on the remaining 15,764 certificates.

In addition remaining stale prices and other data inconsistencies are suspended from the data set. So are observation that cause distortions in the following valuation algorithm. The resulting final data set consists of 14,847 products and 4,703,503 quotes. ${ }^{18}$

Table 1 gives an overview of our final data set, where Panel A consists of our base data and Panel B of our quote data. Reported for Panel A are the initial time to maturity $T_{\text {Initial }}$ in calendar days and the moneyness at issuance $M a I$ divided into long and short leverage

\footnotetext{
${ }^{16}$ The author gratefully acknowledges data from Boerse Stuttgart.

${ }^{17}$ E.g. trailing-stop-loss or one-cancels-other orders. The data set does not contain any further information concerning the characteristics of these orders.

${ }^{18} \mathrm{~A}$ detailed description is provided in the next Section.
} 
certificates on the product level. Moneyness at issuance is defined as DAX/Strike for long and Strike/DAX for short leverage certificates. Summary statistics on Panel B report the remaining time to maturity also in calendar days, the moneyness at quote $M a Q$ and the bid-ask spread.

[Table 1 about here.]

\section{Panel A}

The percentage of long leverage certificates in the final data set is about $57 \%$. On average the initial time to maturity is 72 days for long and 105 days for short certificates. The even smaller median hints at a right skewness of the distribution; $50 \%$ have an initial time to maturity of 54 days or less for long and 84 days or less for short certificates. The mean moneyness at issuance for long and short leverage certificates is about 1.05, this implies that a change in the DAX of $5 \%$ would result in a knock-out. The median is around 1.03 and thus, even smaller. The small moneyness at issuance of the products traded and the rather short-termed time to maturity reflect the high leverage preferences and the speculative investment scope of the investors. In fact, Entrop et al. (2013b) show for a trade data set from an online bank, that the mean holding period is 1.5 calendar days.

\section{Panel B}

In contrast to the literature on structured financial products so far we do not assume a constant spread. For more than $25 \%$ of the products in our data set the spread variates over time. ${ }^{19}$ The major part of the observations in our data set contains spread levels of 1 or 2 cents.

The transaction data is summarized in Table 2. The average traded price, the average volume and the average traded units are separately reported for long and short leverage certificates and market, limit and other orders ${ }^{20}$. Moreover data is divided into buys and sells. The traded price

\footnotetext{
${ }^{19}$ For 4,173 , i.e $28.11 \%$ of all products in our data set the spread is not constant.

${ }^{20}$ Other order types are not pure limit orders like stop-loss or stop-buy orders or more exotic order types like one-cancels-other orders. As the other order typed data shows a complete different picture than the more common
} 
is calculated as the volume weighted averaged price for the time period before a specific quote. Volume values and the traded units are aggregated over the time period before the quote.

[Table 2 about here.]

The data set consists of 185,104 selling trades and of 183,305 buying transactions. Hence in only $5.7 \%(8.7 \%)$ of the quotes in the data set a buy (sell) took place in the time period before the quote. On average the products are bought at a price of 2.29 and sold back at a price of 2.42. We want to stress on one thing here: The average numbers of traded units and also the observation number are larger for buys than for sells for market and limit orders. Reasons may be fourfold: First, the investors often buy smaller amounts of the product and sell back their position as a whole trade, which could lead to a larger observation number of buys in our data set for limit and market orders and the higher averaged traded volume for limit orders. Second, due to the knock-out feature buys must not lead to a sell but can also be a simple loss. As a consequence, the observation number might be smaller for sells. Third, data is excluded off our data set for products with a time to maturity of less than ten days. This is a minor reason though. Finally, the investor has two possibilities to trade products, i.e. at the trading platform of the issuer or directly via the EUWAX. If the investor would prefer one channel for buys or sells this would also be a reason for the imbalance between sells and buys.

market and limit orders and as we have only information on these types, we stress on the effects of limit and market orders in the following. 


\subsubsection{Valuation}

For each quote the fair theoretical value is computed using the pricing model by Rubinstein and Reiner (1991) for down-and-out calls and up-and-out puts:

$$
\begin{aligned}
L C_{0}^{\text {long } B \& S}= & S_{0} \Phi(x)-X \exp (-r T) \Phi(x-\sigma \sqrt{T})- \\
& -S_{0}\left(\frac{X}{S_{0}}\right)^{2 \omega} \Phi(y)+X \exp (-r T)\left(\frac{X}{S_{0}}\right)^{2 \omega-2} \Phi(y-\sigma \sqrt{T}), \\
L C_{0}^{\text {short } B \& S}= & -S_{0} \Phi(-x)+X \exp (-r T) \Phi(-x+\sigma \sqrt{T})+ \\
& +S_{0}\left(\frac{X}{S_{0}}\right)^{2 \omega} \Phi(-y)-X \exp (-r T)\left(\frac{X}{S_{0}}\right)^{2 \omega-2} \Phi(-y+\sigma \sqrt{T})
\end{aligned}
$$

with

$$
x=\frac{\log \left(\frac{S_{0}}{X}\right)}{\sigma \sqrt{T}}+\omega \sigma \sqrt{T}, y=\frac{\log \left(\frac{X}{S_{0}}\right)}{\sigma \sqrt{T}}+\omega \sigma \sqrt{T}, \omega=\frac{r+\frac{\sigma^{2}}{2}}{\sigma^{2}},
$$

where $X>S_{0}$ for short leverage certificates and $S_{0}>X$ for long leverage certificates. $\Phi(\cdot)$ represents the standard normal distribution function. As the model does not include unhedgeable jump risk, the premium for taking this risk should be a part of the calculated markups.

As risk-free interest rate we use interest rates estimated by the German Bundesbank from German governmental bonds for maturities larger than one year and the Eurepo for maturities less than one year. The Eurepo is preferred to the Euribor because in times of high volatility the Euribor is extremely warped. As level of the underlying we use the exact DAX at the second of the quote. Due to limited trading hours of the DAX from 9:00 a.m. till 5:30 p.m., values beyond these periods are approximated by the XDAX. The XDAX is a DAX-substitute calculated from DAX-futures. If necessary the XDAX is interpolated linearly. We eliminate data for which an interpolation with at most 15 seconds time gap is not possible.

The implied volatility of the leverage certificates is computed from options traded on the 
EUREX. The EUREX is an options Exchange where only institutional investors are allowed to trade. Hence options on the EUREX are traded at their fair values. To control for volatility anomalies, we use the method according to Hentschel (2003), which puts more weight on outof-the-money options and overcomes biases of other methods. If there is no perfect match of quote and EUREX option, we use a two-dimensional interpolation via maturity and strike. If this algorithm cannot be applied data is suspended. ${ }^{21}$ Moreover, quotes with an absolute spread larger than 1 and a cover ratio different from 0.01 are eliminated.

So are stale prices. Stale prices are defined as quotes where the bid or ask quotes did not change over at least 5 hours or where new bid or ask quotes are not set during the last 30 minutes. Due to possible valuation sensitivities bid or ask quotes which are smaller than 45 cents and quotes with a smaller remaining time to maturity than 10 days are also excluded from the data set (compare Entrop et al., 2013b). Last we eliminate the 1\% outlying observations with the highest and lowest markups. The resulting final data set consists of 14,847 products and 4,703,503 quotes.

To analyze the issuers price-setting we focus on the margins earned by the issuer. Therefore we compare the calculated fair values $L C^{\text {model }}$ according to (15) with the mid quotes $L C^{\text {mid }}$. We calculate the mid quotes from our data set as the arithmetic mean of the bid and the ask quotes:

$$
L C^{\text {mid }}=\frac{L C^{a s k}+L C^{b i d}}{2}
$$

In a second step we calculate absolute $A P$ and relative differences $R P$ of the model prices and

\footnotetext{
${ }^{21}$ For further information see Hentschel (2003); Entrop et al. (2013b); Baule (2011).
} 
the mid quotes:

$$
\begin{aligned}
& A P=L C^{\text {mid }}-L C^{\text {model }}, \\
& R P=\frac{L C^{\text {mid }}-L C^{\text {model }}}{L C^{\text {model }}} .
\end{aligned}
$$

Summary statistics of the premiums are reported in Table 3. The results are shown separately for each moneyness at quote quintile and short and long leverage certificates.

[Table 3 about here.]

Absolute (relative) premiums in total over all quintiles of moneyness for long certificates are about 17 cents (5.5\%) and for short certificates 15 cents (6.6\%) respectively. Hence issuers charge a higher absolute (relative) premium for long (short) certificates and vice versa. Moreover we see a moneyness effect of the premiums. Absolute and relative premiums are the larger the smaller the moneyness at quote. Hence, the nearer the product is listed at the barrier the higher the premium. The reason may be order flow or gap risk-driven. In fact, the gap risk is more relevant the higher the probability for a knock-out which is highly correlated with the moneyness. The same applies for the order flow: In the first moneyness quintile nearly $25 \%$ of the observations are a traded quote, whereas in the fifth quintile it is barely $1 \%$.

\subsection{Regression analysis design}

To analyse the determinants of the premium and to test the model-derived hypotheses from Section 2, we lean on the regression approach by Entrop et al. (2013a) and expand it by some 
factors. We run the following regression for five moneyness at quote quintiles separately:

$$
\begin{aligned}
A P_{i}=\text { const } & +\beta \text { RelTtM }_{i} \\
& +\sum_{j m n} \delta_{j m n} 1_{\left\{\text {HourDummy }_{i} \in \text { HourDummy }_{j}\right.} \text { OrderDummy }_{i} \times \text { BuySellDummy }_{n i} \times \text { Volume }_{i} \\
& +\sum_{p} \zeta_{p} \text { HourDummy }_{p i} \times \text { OvernightVolatility }_{i} \\
& +\sum_{j q} \eta_{j q} 1_{\left\{\text {HourDummy }_{i} \in \text { HourDumm }_{j}\right\}} \text { LongDummy }_{q i} \times \text { SlopeSmile }_{i} \\
& +\theta \text { Spread }_{i} \\
& +\kappa \text { LongDummy }_{i} \\
& +\sum_{r} \lambda_{r} \text { Controls }_{r i}+\varepsilon_{i},
\end{aligned}
$$

where $A P$ stands for the absolute premium calculated as in (3) for each quote $i$ in the data set. ${ }^{22}$ The regression can be separated into several parts that consider the above hypotheses.

\section{Hypothesis 1: $\operatorname{relTt} M_{i}$}

The relative time to maturity $\operatorname{relTt} M$ is defined as:

$$
\text { relTtM }=\frac{\text { Remaining Time to Maturity }}{\text { Initial Time to Maturity }}
$$

We test the life cycle hypothesis with this regression part and therefore would expect a positive $\beta$ if Hypothesis 1 holds. Certificates with an increasing remaining time to maturity at a given initial time to maturity, hence products with a longer time of their life time left, would have higher premiums. We would expect a divergence in this effect for different levels of moneyness though. With larger moneyness at quote quintiles the effect should be larger (Entrop et al.,

\footnotetext{
${ }^{22}$ Running the regression with relative premiums does not change our results.
} 
2013b), because the life cycle hypothesis might be more pronounced for products with higher moneyness.

\section{Hypothesis 2: Volume $_{i}$}

To test Hypothesis 2 we calculate hourly trading fractions of the aggregated trading volume for each day and product separately for market and limit orders and also for buys and sells. If no respective trade occurred in the subsequent time period of the quote the fraction value is set to zero. We expect different effects during the day according to the buy-sell relation. In Figure 5 is shown the extraordinary buy-sell relation during the course of the day. Extraordinary in this context means divergence from the daily mean buy-sell-fraction. Before 4:00 p.m. on average we can see more extraordinary buying-activity than selling-activity. After 4:00 p.m. this relation reverses and we can see a much higher extraordinary selling activity. Therefore we measure the effects also for two different periods of time, which map the investors' intra-day trading behavior best: The first time period is from market start until 4:00 p.m., the second covers quotes later than 4:00 p.m. until the market is closed.

[Figure 5 about here.]

We suggest the coefficients $\delta_{j m n}$ to be positive (negative) for buys if buys (sells) dominate, because this would be equivalent to an extraordinary demand increase (decrease) in Chapter 2.3. For sells it should be exactly opposite.

According to the equity literature the volume-return relation may suffer from endogeneity (e.g. Chen, 2012; Dorn et al., 2008). In comparison to the equity markets this is a rather unimportant problem in our context. First we do not examine returns but markups of the issuer. The correlation between the absolute markup and the mid-quote is only $-5 \%$. Hence the return does not represent the markup of the issuer at all. Nevertheless we assume in the theoretical model that the investors have a certain guess about the level of the markups. Therefore markups 
could have an influence on the order flow as well. There are some important arguments that weaken or even negate this relation. First, for our analysis we aggregate volume up to the point in time of the quote. Hence we precisely use at most lagged volume data for the explanation of the markup which can hardly be influenced by unknown future markups. Moreover we distinguish between market and limit orders. Especially limit order placements often do not coincide with the time of execution of the order and are based upon conditions and expectations at the point in time when the order is placed. For market orders this relation does not hold though. This is one reason for distinguishing between these two order types.

\section{Hypothesis 3: OvernightVolatility}

With $\zeta_{p}$ we analyze the intra-day pricing behavior of the market maker due to the overnight gap risk and test Hypothesis 3. As a proxy we use overnight DAX volatility forecasts. Precisely, we take the first and last available DAX or XDAX level and calculate the overnight returns. Then we forecast the overnight volatility via a $\operatorname{Garch}(1,1)$ approach according to Engle (1982); Bollerslev (1986).

To control for a possible intra-day pricing behavior the effect of OvernightVolatility is calcu- $^{-}$ lated separately for each hour within the day. We suggest $\zeta_{p}$, i.e. the influence of the gap risk proxy on the pricing behavior, to be positive and to increase within the course of the day.

\section{Hypothesis 3: SlopeSmile $_{i}$}

According to Arisoy (2014) we use the implied volatility slope calculated from OTM puts as a proxy for the overall downside jump risk of the DAX and the resulting gap risk for the issuer. Compared to portfolios, which have been used in earlier studies (e.g., Ang et al., 2006), the implied volatility skew is a more precise measure of the systematic jump risk at the stock level (Yan, 2011) and also cross-sectional (Cremers et al., 2013). We use settlement prices of EUREX options with a maturity of 1 month and the respective implied volatilities calculated by the 
method according to Chapter 3.2 and Hentschel (2003). In the case that options with an exact maturity of 30 days are not available, we interpolate. The measure of the slope is calculated as the difference between the implied volatility of out-of-the-money puts with moneyness $m=0.98$ and at-the-money calls, $s l \equiv \sigma_{\text {put }}^{i m p}(m)-\sigma_{\text {call }}^{\text {imp }}(1)$. We measure the effect of the overall jump risk separately for long and short certificates and the first part and the second part of the day. The respective coefficients $\eta_{j q}$ are supposed to be positive for long certificates and negative for short certificates, because a knock-out is only possible for long leverage certificates if a negative jump occurs. Therefore a higher jump risk increases the premiums for long and decreases the premiums for short leverage certificates. A knock-out may only occur if the underlying market is open. Therefore the effect of the overall jump risk on the premium should be more pronounced during the first part of the day.

\section{Hypothesis 4: Spread $_{i}$}

According to our solutions in Chapter 2.3.2 we would expect a negative $\theta$, i.e. a negative effect of the spread on the premium, due to compensation effects with respect to the profit and the demand function of the issuer. As also shown in the theoretical model the relation between spread and markup might suffer from an endogeneity issue. Since we are only interested in explaining the issuers price-setting behavior, we use a 2SLS-approach to control for this possible endogeneity. We use two instruments for the spread:

i) The average spread over all products of the prior day,

ii) The first difference of the ratio between the spread of the most similar product and the average spread of the same day.

Due to the spread signal effect, the issuer has a certain pressure to set the spread around the general averaged level of the spread in the market. Hence the lagged daily spread average is a good proxy for the spread. The second instrument of our analysis is the first difference of 
the spread of the most similar product in proportion to the daily spread average of the same day. As most similar product we choose a product listed at the same time in the market as the reference quote issued by a different issuer. We measure the similarity between all relevant products and the reference quote along the dimensions relative time to maturity and moneyness at quote. We first transform the moneyness and the time to maturity in the euclidean space according to Torgerson (1958). Then we calculate the euclidean distance between the reference observation and the other quotes according to the following formula:

$$
d(p, q)=\sqrt{\left(p_{1}-q_{1}\right)^{2}+\left(p_{2}-q_{2}\right)^{2}}
$$

where $p_{i}$ and $q_{i}$ are the transformed moneyness at quote and relative time to maturity for the two compared observations. The spread of the product with the smallest distance is then used as part of the instrument. If several products with the same distance existed we use the arithmetic mean of the spreads.

In order to get unbiased estimators we test the above instruments according to their validity and relevance via Wooldrige's score test of overidentifying restrictions (Wooldridge, 1995) and an F-test for the joint significance of the first stage instruments' coefficients. Moreover, we test for endogeneity of the spread via an approach following Hausman (1978) and Wooldridge's score test for endogeneity (Wooldridge, 1995). All instruments are valid at least at a 10\% significance level. The null hypothesis of the relevance ${ }^{23}$ and endogeneity test can be rejected at a $1 \%$ significance level. Hence the instruments are valid and relevant and the spread is indeed endogenous.

\section{Controls $_{s i}$}

The effect of the long dummy $\kappa$ is supposed to be positive reflecting the already reported lower premiums for short certificates.

\footnotetext{
${ }^{23}$ Stock et al. (2002) suggest that the F-Statistic has to exceed a level of 10, which is also verified for our tests.
} 
Due to using different products from different issuers over a time period of two and a half year, we have to control for some fixed effects. These fixed effects are very unlikely product specific fixed effect, because the same issuer would not set different markup levels for his products without a reason. We rather assume issuer and quarter specific level differences in the markups. Therefore we include quarter and issuer dummies in the regression model.

Moreover, the original time to maturity divided into quintiles is used as a control variable. The markups might be melted diversely for different original life times of the products.

Besides, to calculate the implied volatility for the valuation of the products we used settlement prices of EUREX options rather than prices at the time of the quote. According to Wallmeier (2012), 95\% of the intra-day variation of implied volatility can be explained by changes in the index level. Therefore we use the DAX return from the quote time until the settlement time of the day as a control variable for intra-day changes of the volatility smile.

Additionally, on Fridays the set markups could be higher due to the longer trading break and unsure information arrival during the weekend. The gap risk faced by the issuer might be increased, which might have consequences for the price-setting. We control for this effect via a Friday dummy.

\subsection{Regression results}

The results of regression (19) can be found in Table 4. The coefficient of the relative time to maturity is positive significant at a $0.1 \%$ level. Moreover, the effect becomes larger for increasing quintiles of moneyness. This is conform to the life cycle Hypothesis 1, i.e. products with a higher remaining time to maturity have larger premiums. Additionally, the less likely the knock-out of the product, the stronger is the indication for the life cycle hypothesis.

The regression coefficient of market and limit order typed buys is, at least for the first mon- 
eyness quintiles, negative for the second part of the day and positive or less negative beforehand. The significance is more pronounced for limit orders and the second part of the day though. The effects of the extraordinary trading behavior on the markup can be summed up as follows: A buy increases (decreases) the markup in times where more buys (sells), representing a positive (negative) demand shift, are probable, i.e. the first (second) part of the day. The reason why the issuer can anticipate this behavior is straight forward. In this special market the issuer knows exactly which quantity will be given back in the future, i.e. at most the quantity which has been bought before a certain point in time. This is because the investor's only trading partner is the issuer once he has bought the product. The investor has only two choices: Either to hold the product and risk a knock-out or to sell it back. The influence of the sell order is, as suggested, reverse and less significant. This is reasonable because the effect of sells are not as predictable as the effects of buys for the issuer. This observation is consistent with Hypothesis 2, whereas the order flow is priced differently for a buy or a sell order.

The hourly effects of the overnight gap risk are also at most positive and significant at a $0.1 \%$ level. Moreover, the effect is larger for the second half of the day and it becomes less clear for increasing moneyness quintiles. In fact, the effects are negative significant for the last moneyness quintile. Hence, the pricing of the overnight gap risk is more pronounced for frequently traded products and products which are listed closer to the knock-out barrier, which is the case within the first moneyness quintile. This leads to the conclusion that intra-daily higher premiums are charged with the proximity of the overnight gap, which is equivalent to Hypothesis 3 .

The coefficients of the slope smile differ, as suggested, for long and short certificates. The effect is positive for long and negative for short certificates, because the overall jump risk of the underlying is negatively correlated with a knock-out for short and positively correlated for 
long certificates. Moreover the effect is less distinctive for the second part of the day, where the products cannot knock-out. Hence, also a higher probability of over all jump events, as an example of unhedgeable risk events, increases the markups, which is also consistent with Hypothesis 3.

The effect of the spread is positive significant at a $0.1 \%$ significance level for all five moneyness quintiles. Hence a larger spread leads to larger markups. This contradicts Hypothesis 4, where we suggested that the spread and the markup are substitutes. However, if the investors were not able to evaluate the markups in such a refined way as we suggested in our model, the demand would only be affected modestly by an increase in the markups and the issuer could compensate losses caused by an increased spread via a rise in the markups. This is a reasonable explanation and suggests that the demand sensitivity of the investors towards the markup level is of minor importance whereas the sensitivity towards the spread is higher, which is again consistent with our model assumptions.

[Table 4 about here.]

\section{Conclusion}

In this paper we concentrated on the issuer's price-setting in the market for retail certificates. In the first part we evolved the first theoretical model that derives the optimal price-setting behavior. We detected an explanation of already well-known interrelations as the life cycle and the order flow hypothesis, but were also able to concretize these findings and to set light on some additional factors moving the issuers price-setting. The (intra-day) structure of the optimal price setting is foremost affected by the unhedgeable risk faced by the issuer, the (intra-day) order flow and also the fraction of investors that hold the product beyond the unhedgeable risk event.

Actually we determine the unhedgeable risk as one major driver of the issuers markup. Hence 
the markups are the higher the closer comes the unhedgeable risk event. In our model the spread is no longer constant but also an endogenous variable, which interacts with the markups. We separated the spread effect into a pure spread effect, where the issuer compensates a larger spread via a smaller markup level and vice versa and a more important signal effect, where the spread is the visible signal for the price quality in the market.

These hypotheses are scrutinized empirically by means of a data set of quotes of finite leverage certificates on the blue-chip index DAX on the German market for the second quarter of 2009 till the third quarter of 2011. We used the standard Black-Scholes-Model to extract the markups including the unhedgeable risk charged by the issuers. To analyze if we can verify the model-based hypotheses we used a 2SLS approach due to an endogeneity matters between the spread and the markups.

Our main findings are that the overpricing decreases over the product's life time, that the issuers distinguish between times of extraordinary selling and buying activities and buy and sell orders according to their order flow pricing behavior. Moreover do we find that the markups are larger at the end of the day due to the proximity of the overnight gap. The overall jump risk has a decreasing effect on the premiums of short and an increasing effect on the premiums of long certificates. The only major discrepancy between the model-derived hypotheses and the empirical analysis is the effect of the spread. Confronted to the theoretical model the spread effect on the premiums is positive, which may refer to a small investors' demand sensitivity towards the markups. 


\section{Appendix A Special case 1: Holding until maturity}

The optimization problem is given by:

$$
\max _{\alpha_{0}, \alpha_{1}, \alpha_{2}, v} \pi=\left(\alpha_{0}-g\right) D_{0}+\left(\alpha_{1}-g\right) D_{1}+\left(\alpha_{2}-g\right) D_{2} \quad \text { s.t. } \quad D_{i} \geq 0, v \geq 0
$$

First order conditions are given by:

$$
\begin{array}{lll}
\frac{\partial \pi}{\partial \alpha_{0}}=x-v^{2} z-2 \alpha_{0} y+g y & \stackrel{!}{=} 0 \\
\frac{\partial \pi}{\partial \alpha_{1}}=x+w_{1}-v^{2} z-2 \alpha_{1} y+g y & & \stackrel{!}{=} 0 \\
\frac{\partial \pi}{\partial \alpha_{2}}=x+w_{2}-v^{2} z-2 \alpha_{2} y+g y & & ! \\
\frac{\partial \pi}{\partial v} & =-2 v z\left(\alpha_{0}+\alpha_{1}+\alpha_{2}-3 g\right) &
\end{array}
$$

These equations can easily be solved. The sufficient second order condition for $\pi\left(\alpha_{0}^{*}, \alpha_{1}^{*}, \alpha_{2}^{*}, v^{*}\right)$ being a local maximum is a negative definite Hessian $H_{\pi}$. The Hessian reads

$$
H_{\pi}\left(\alpha_{0}^{*}, \alpha_{1}^{*}, \alpha_{2}^{*}, v^{*}\right)=\left\{\begin{array}{cccc}
-2 y & 0 & 0 & -2 v^{*} z \\
0 & -2 y & 0 & -2 v^{*} z \\
0 & 0 & -2 y & -2 v^{*} z \\
-2 v^{*} z & -2 v^{*} z & -2 v^{*} z & -2 z\left(a_{0}^{*}+a_{1}^{*}+a_{2}^{*}-3 g\right)
\end{array}\right\}
$$

which is always negative definite for the in the model assumed sufficiently large $x$, which can be derived from Sylvester's criterion based on the leading principal minors. 


\section{Appendix B Special case 2: Giving back at the next point in}

\section{time}

The optimization problem is given by:

$$
\max _{\alpha_{0}, \alpha_{1}, \alpha_{2}, v} \pi=\left(\alpha_{0}-\alpha_{1}+v\right) D_{0}+\left(\alpha_{1}-\alpha_{2}+v\right) D_{1}+\left(\alpha_{2}-g\right) D_{2} \quad \text { s.t. } \quad D_{i} \geq 0, v \geq 0
$$

First order conditions are given by:

$$
\begin{array}{lll}
\frac{\partial \pi}{\partial \alpha_{0}}=x-v^{2} z+y\left(\alpha_{1}-2 \alpha_{0}-v\right) & \stackrel{!}{=} 0 \\
\frac{\partial \pi}{\partial \alpha_{1}}=w_{1}+y\left(\alpha_{0}+\alpha_{2}-2 \alpha_{1}-v\right) & \stackrel{!}{=} 0 \\
\frac{\partial \pi}{\partial \alpha_{2}}=w_{2}-w_{1}+y\left(\alpha_{1}-2 \alpha_{2}+g\right) & \stackrel{!}{=} 0 \\
\frac{\partial \pi}{\partial v}=2 x+w_{1}-\alpha_{0} y-\alpha_{1} y-2 v^{2} z-2 v z\left(\alpha_{0}+2 v-g\right) & \stackrel{!}{=} 0
\end{array}
$$

The Hessian reads:

$$
H_{\pi}\left(\alpha_{0}^{*}, \alpha_{1}^{*}, \alpha_{2}^{*}, v^{*}\right)=\left\{\begin{array}{cccc}
-2 y & y & 0 & -y-2 v^{*} z \\
y & -2 y & y & -y \\
0 & y & -2 y & 0 \\
-y-2 v^{*} z & -y & 0 & -2 z\left(a_{0}^{*}+6 v^{*}-g\right)
\end{array}\right\}
$$

which is negative definite if the above solutions hold due to the assumption of $x$ being sufficiently large and $g, z, y$ being sufficiently small, which can be derived from Sylvester's criterion based on the leading principal minors. 


\section{Appendix C Complete model}

The optimization problem is given by:

$\max _{\alpha_{0}, \alpha_{1}, \alpha_{2}, v} \pi_{a g g}=\left(\alpha_{0}-\gamma_{1}\left(\alpha_{1}-v\right)-\left(1-\gamma_{1}\right) g\right) D_{0}+\left(\alpha_{1}-\gamma_{2}\left(\alpha_{2}-v\right)-\left(1-\gamma_{2}\right) g\right) D_{1}+\left(\alpha_{2}-g\right) D_{2}$

s.t. $\quad D_{i} \geq 0, v \geq 0$

First order conditions are given by:

$$
\begin{array}{rlrl}
\frac{\partial \pi}{\partial \alpha_{0}} & =x-v^{2} z-2 \alpha_{0} y+g y+\gamma\left(\alpha_{1} y-v y-g y\right) & \stackrel{!}{=} 0 \\
\frac{\partial \pi}{\partial \alpha_{1}}=w_{1}-2 \alpha_{1} y+\gamma\left(\alpha_{0} y+\alpha_{2} y-v y\right)+(1-\gamma)\left(x+g y-v^{2} z\right) & \stackrel{!}{=} 0 \\
\frac{\partial \pi}{\partial \alpha_{2}}=w_{2}-2 \alpha_{2} y+g y+\gamma\left(\alpha_{1} y-w_{1}\right)+(1-\gamma)\left(x-v^{2} z\right) & \stackrel{!}{=} 0 \\
\frac{\partial \pi}{\partial v}=2 v z\left(g-\alpha_{0}\right)+\gamma\left(2 x+w_{1}-\alpha_{0} y-\alpha_{1} y-6 v^{2} z\right)+2 v z(1-\gamma)\left(2 g-\alpha_{1}-\alpha_{2}\right) & \stackrel{!}{=} 0
\end{array}
$$

The Hessian reads:

$$
H_{\pi}\left(\alpha_{0}^{*}, \alpha_{1}^{*}, \alpha_{2}^{*}, v^{*}\right)=\left\{\begin{array}{cccc}
-2 y & \gamma y & 0 & -2 v^{*} z-\gamma y \\
\gamma y & -2 y & \gamma y & -2 v^{*} z(1-\gamma)-\gamma y \\
0 & \gamma y & -2 y & -2 v^{*} z(1-\gamma) \\
-2 v^{*} z-\gamma y & -2 v^{*} z(1-\gamma)-\gamma y & -2 v^{*} z(1-\gamma) & -12 v^{*} y z-2 z\left(a_{0}^{*}-g\right)- \\
& & \left.-2 z(1-\gamma)\left(\alpha_{0}^{*}+\alpha_{1}^{*}-2 g\right)\right)
\end{array}\right\}
$$

which is negative definite if the above solutions hold due to the assumption of $x$ being sufficiently large and $g, z, y$ being sufficiently small, which can be derived from Sylvester's criterion based on the leading principal minors. 


\section{References}

Ang, A., Chen, J., Xing, Y., 2006. Downside risk. Review of Financial Studies 19, 1191-1239.

Arisoy, Y. E., 2014. Aggregate volatility and market jump risk: An option-based explanation to size and value premia. Journal of Futures Markets 34, 34-55.

Baubonis, C., Gastineau, G. L., Purcell, D., 1993. The banker's guide to equity-linked certificates of deposit. Journal of Derivatives 1 (Winter), 87-95.

Baule, R., 2011. The order flow of discount certificates and issuer pricing behavior. Journal of Banking and Finance 35, 3120-3133.

Baule, R., Blonski, P., 2013. The demand for warrants and issuer pricing strategies. Working Paper (October 2013), University of Hagen.

Baule, R., Entrop, O., Wilkens, M., 2008. Credit risk and bank margins in structured financial products: Evidence from the German secondary market for discount certificates. Journal of Futures Markets 28, 376-397.

Baule, R., Tallau, C., 2011. The pricing of path-dependent structured financial retail products: The case of bonus certificates. Journal of Derivatives 18 (Summer), 54-71.

Benet, B. A., Giannetti, A., Pissaris, S., 2006. Gains from structured product markets: The case of reverse-exchangeable securities (RES). Journal of Banking and Finance 30, 111-132.

Bernard, C., Boyle, P. P., Gornall, W., 2009. Locally-capped investment products and the retail investor. Journal of Derivatives 19 (Winter), 72-88.

Bollerslev, T., 1986. Generalized autoregressive conditional heteroskedasticity. Journal of Econometrics 31 (3), 307-327.

Branger, N., Breuer, B., 2008. The optimal demand for retail derivatives. Working Paper (March 2008), University of Muenster and Goethe University Frankfurt.

Breuer, W., Perst, A., 2007. Retail banking and behavioral financial engineering: The case of structured products. Journal of Banking and Finance 31, 827-844.

Bulow, J. I., 1982. Durable-goods monopolists. The Journal of Political Economy 90, 314-332.

Burth, S., Kraus, T., Wohlwend, H., 2001. The pricing of structured products in the Swiss market. Journal of Derivatives 9 (Winter), 30-40.

Carr, P., Ellis, K., Gupta, V., 1998. Static hedging of exotic options. The Journal of Finance $53,1165-1190$.

Chen, A., Kensinger, J., 1990. An analysis of market-index certificates of deposit. Journal of Financial Services Research 4 (2), 93-110.

Chen, K. C., Sears, R. S., 1990. Pricing the SPIN. Financial Management 19, 36-47.

Chen, S.-S., 2012. Revisiting the empirical linkages between stock returns and trading volume. Journal of Banking and Finance 36, 1781-1788.

Coase, R. H., 1972. Durability and monopoly. Journal of Law and Economics 15, 143-149. 
Cremers, M., Halling, M., Weinbaum, D., 2013. Aggregate jump and volatility risk in the crosssection of stock returns. Working Paper (October 2013), University of Notre Dame, Swedish House of Finance, University of Utah and Syracuse University.

Desai, P., Purohit, D., 1998. Leasing and selling: Optimal marketing strategies for a durable goods firm. Management Science 44 (11), 19-34.

Dorn, D., 2012. Investors with too many options? Working Paper (October 2012), LeBow College of Business, Drexel University.

Dorn, D., Huberman, G., Sengmueller, P., 2008. Correlated trading and returns. The Journal of Finance 63, 885-920.

Engle, R. F., 1982. Autoregressive conditional heteroscedasticity with estimates of the variance of United Kingdom inflation. Econometrica 50, 987-1007.

Entrop, O., McKenzie, M., Wilkens, M., Winkler, C., 2013a. The performance of individual investors in structured financial products. Working Paper (January 2013), University of Passau and University of Augsburg.

Entrop, O., Schober, A., Wilkens, M., 2012. The impact of greed and experience on private investors' returns and banks' margins: The case of short-term exchange-traded retail products. Working Paper (August 2012), University of Passau and University of Augsburg.

Entrop, O., Schober, A., Wilkens, M., 2013b. The pricing policy of banks on the german secondary market for leverage certificates: Interday and intraday effects. Working Paper (March 2013), University of Passau and University of Augsburg.

Garman, M. B., 1976. Market microstructure. Journal of Financial Economics 3, 257-275.

Glosten, L. R., Milgrom, P. R., 1985. Bid, ask and transaction prices in a specialist market with heterogeneously informed traders. Journal of Financial Economics 14, 71-100.

Grünbichler, A., Wohlwend, H., 2005. The valuation of structured products: Empirical findings for the Swiss market. Financial Markets and Portfolio Management 19, 361-380.

Hasbrouck, J., Sofianos, G., 1993. The trades of market makers: An empirical analysis of NYSE specialists. The Journal of Finance 48, 1565-1593.

Hausman, J. A., 1978. Specification tests in econometrics. Econometrica 46, 1251-1271.

Henderson, B. J., Pearson, N. D., 2011. The dark side of financial innovation: A case study of the pricing of a retail financial product. Journal of Financial Economics 100, 227-247.

Hentschel, L., 2003. Errors in implied volatility estimation. The Journal of Financial and Quantitative Analysis 38, 779-810.

Hernández, R., Lee, W. Y., Liu, P., Dai, T.-S., 2013. Outperformance certificates: Analysis, pricing, interpretation, and performance. Review of Quantitative Finance and Accounting 40 (4), 691-713.

Ho, T. S., Stoll, H. R., 1981. Optimal dealer pricing under transactions and return uncertainty. Journal of Financial Economics 9, 47-73. 
Ho, T. S., Stoll, H. R., 1983. The dynamics of dealer markets under competition. The Journal of Finance 38, 1053-1074.

Huang, R. D., Stoll, H. R., 1996. Dealer versus auction markets: A paired comparison of execution costs on NASDAQ and the NYSE. Journal of Financial Economics 41, 313-357.

Kyle, A. S., 1985. Continuous auctions and insider trading. Econometrica 53, 1315-1335.

Lord, N., 2011. Banks battle for structured products business. Euromoney 41 (509).

Mahayni, A., Suchanecki, M., 2006. Produktdesign und Semi-Statische Absicherung von TurboZertifikaten. Zeitschrift für Betriebswirtschaft 76, 347-372.

Meyer, S., Schroff, S., Weinhardt, C., 2013. (Un)skilled leveraged trading of retail investors. Working Paper (February 2013), Karlsruhe Institute of Technology and University of Hohenheim.

Muck, M., 2006. Where should you buy your options? The pricing of exchange-traded certificates and OTC derivatives in Germany. Journal of Derivatives 14 (Fall), 82-96.

Rubinstein, M., Reiner, E., 1991. Breaking down the barriers. Risk 4 (8), 28-35.

Schroff, S., Meyer, S., Burghof, H.-P., 2013. Individual investor trading in leverage productsrisk appetite and positioning around earnings announcements. Working Paper (August 2013), Karlsruhe Institute of Technology and University of Hohenheim.

Stock, J. H., Wright, J. H., Yogo, M., 2002. A survey of weak instruments and weak identification in generalized method of moments. Journal of Business and Economic Statistics 20, 518-529.

Stoimenov, P. A., Wilkens, S., 2005. Are structured products "fairly" priced? An analysis of the German market for equity-linked instruments. Journal of Banking and Finance 29, 2971-2993.

Stokey, N. L., 1981. Rational expectations and durable goods pricing. The Bell Journal of Economics 12, 112-128.

Stoll, H. R., 1978. The supply of dealer services in securities markets. Journal of Finance 33, $1133-1151$.

Szymanowska, M., Horst, J. T., Veld, C., 2009. Reverse convertible bonds analyzed. Journal of Futures Markets 29, 895-919.

Torgerson, W. S., 1958. Theory and methods of scaling, Wiley.

Wallmeier, M., 2012. Smile in motion: An intraday analysis of asymmetric implied volatility. Working Paper (August 2012), University of Fribourg.

Wallmeier, M., Diethelm, M., 2009. Market pricing of exotic structured products: The case of multi-asset barrier reverse convertibles in Switzerland. Journal of Derivatives 17 (Winter), $59-72$.

Wasserfallen, W., Schenk, C., 1996. Portfolio insurance for the small investor in Switzerland. Journal of Derivatives 3 (Spring), 37-43.

White, H., 1980. A heteroskedasticity-consistent covariance matrix estimator and a direct test for heteroskedasticity. Econometrica 48, 817-838. 
Wilkens, S., Erner, C., Röder, K., 2003. The pricing of structured products in Germany. Journal of Derivatives 11 (Fall), 55-69.

Wilkens, S., Stoimenov, P. A., 2007. The pricing of leverage products: An empirical investigation of the German market for "long" and "short" stock index certificates. Journal of Banking and Finance 31, 735-750.

Wooldridge, J. M., 1995. Score diagnostics for linear models estimated by two stage least squares. In: Maddala, G. S., Phillips, P. C., Srinivasan, Nilakanta, T. (Eds.), Advances in Econometrics and Quantitative Economics: Essays in Honor of Professor C. R. Rao. Blackwell, Oxford, pp. 66-87.

Yan, S., 2011. Jump risk, stock returns, and slope of implied volatility smile. Journal of Financial Economics 99, 216-233. 


\section{Tables}

Table 1: Certificates Base Data and Quote Data

Panel A: Base Data

Initial Time to Maturity $T_{\text {initial }}$

\begin{tabular}{llllll} 
& $P 25$ & Mean & Median & $P 75$ & $N$ \\
\cline { 2 - 6 }$L C^{\text {long }}$ & 35 & 72 & 54 & 94 & 8,519 \\
$L C^{\text {short }}$ & 48 & 105 & 84 & 145 & 6,328 \\
\hline Total & 40 & 86 & 62 & 117 & 14,847 \\
\hline
\end{tabular}

Moneyness at Issuance $M a I$

\begin{tabular}{llllll} 
& $P 25$ & Mean & Median & $P 75$ & $N$ \\
\cline { 2 - 6 }$L C^{\text {long }}$ & 1.0129 & 1.0503 & 1.0260 & 1.0637 & 8,519 \\
$L C^{\text {short }}$ & 1.0165 & 1.0542 & 1.0345 & 1.0741 & 6,328 \\
\hline Total & 1.0142 & 1.0520 & 1.0296 & 1.0689 & 14,847 \\
\hline \hline
\end{tabular}

Panel B: Quote Data

Remaining Time to Maturity

\begin{tabular}{llllll} 
& $P 25$ & Mean & Median & $P 75$ & $N$ \\
\cline { 2 - 6 }$L C^{\text {long }}$ & 29 & 67 & 51 & 93 & $2,617,056$ \\
$L C^{\text {short }}$ & 40 & 97 & 78 & 132 & $2,086,447$ \\
\hline Total & 33 & 81 & 62 & 112 & $4,703,503$ \\
\hline
\end{tabular}

Moneyness at Quote $M a Q$

\begin{tabular}{llllll} 
& $P 25$ & Mean & Median & $P 75$ & $N$ \\
\cline { 2 - 6 }$L C^{\text {long }}$ & 1.0453 & 1.1002 & 1.0805 & 1.1338 & $2,617,056$ \\
$L C^{\text {short }}$ & 1.0360 & 1.0775 & 1.0638 & 1.1034 & $2,086,447$ \\
\hline Total & 1.0453 & 1.0901 & 1.0724 & 1.1194 & $4,703,503$ \\
\hline
\end{tabular}

Spread

\begin{tabular}{llllll} 
& $P 25$ & Mean & Median & $P 75$ & $N$ \\
\cline { 2 - 6 }$L C^{\text {long }}$ & 0.01 & 0.0130 & 0.01 & 0.02 & $2,617,056$ \\
$L C^{\text {short }}$ & 0.01 & 0.0140 & 0.01 & 0.02 & $2,086,447$ \\
\hline Total & 0.01 & 0.0134 & 0.01 & 0.02 & $4,703,503$ \\
\hline \hline
\end{tabular}

Composition of the certificates data set separated for base and quote data. For each variable are shown the number of products or quotes $N$, Mean, Median and the $25 \%$ and $75 \%$ quantiles $P 25$ and P75. Results are reported separately for long leverage certificates $L C^{l o n g}$ and short leverage certificates $L C^{\text {short }}$. Panel A refers to the base data of the products: Time to maturity in calendar days $T_{\text {Inital }}$ and moneyness at issunce MaI (= DAX/Strike for long mat Strike/DAX for short leveral and certificates). Pat and $S$ trike/DAX for short leverage certificates). Panel $B$ refers to the quote data: Remaining spread.
sprime to maturity in calendar days, moneyness at the time of the quote $M a Q$ and the bid-ask 
Table 2: Transaction Data

\begin{tabular}{|c|c|c|c|c|c|c|}
\hline & \multicolumn{2}{|c|}{ Long Certificates } & \multicolumn{2}{|c|}{ Short Certificates } & \multicolumn{2}{|c|}{ Total } \\
\hline & Mean & $N$ & Mean & $N$ & Mean & $N$ \\
\hline \multicolumn{3}{|l|}{ Limit Orders } & \multicolumn{2}{|c|}{ Buys } & & \\
\hline $\begin{array}{l}\text { Price } \\
\text { Volume } \\
\text { \#Trades }\end{array}$ & $\begin{array}{l}1.63 \\
3383.1 \\
1.40\end{array}$ & $\begin{array}{l}58,677 \\
58,677 \\
58,677\end{array}$ & $\begin{array}{l}1.60 \\
4298.6 \\
1.45\end{array}$ & $\begin{array}{l}73,286 \\
73,286 \\
73,286\end{array}$ & $\begin{array}{l}1.61 \\
3891.5 \\
1.43\end{array}$ & $\begin{array}{l}131,963 \\
131,963 \\
131,963\end{array}$ \\
\hline \#Trades & \multicolumn{6}{|c|}{ Sells } \\
\hline $\begin{array}{l}\text { Price } \\
\text { Volume } \\
\text { \#Trades }\end{array}$ & $\begin{array}{l}2.02 \\
3588.6 \\
1.22\end{array}$ & $\begin{array}{l}36,984 \\
36,984 \\
36,984\end{array}$ & $\begin{array}{l}1.86 \\
4478.6 \\
1.28\end{array}$ & $\begin{array}{l}43,721 \\
43,721 \\
43,721\end{array}$ & $\begin{array}{l}1.94 \\
4070.8 \\
1.25\end{array}$ & $\begin{array}{l}80,705 \\
80,705 \\
80,705\end{array}$ \\
\hline \multicolumn{3}{|l|}{ Market orders } & \multicolumn{2}{|c|}{ Buys } & & \\
\hline $\begin{array}{l}\text { Price } \\
\text { Volume } \\
\text { \#Trades }\end{array}$ & $\begin{array}{l}2.49 \\
4087.1 \\
1.24\end{array}$ & $\begin{array}{l}28,665 \\
28,665 \\
28,665\end{array}$ & $\begin{array}{l}2.26 \\
5130.8 \\
1.24\end{array}$ & $\begin{array}{l}36,350 \\
36,350 \\
36,350\end{array}$ & $\begin{array}{l}2.36 \\
4670.6 \\
1.24\end{array}$ & $\begin{array}{l}65,015 \\
65,015 \\
65,015\end{array}$ \\
\hline \#Trades & \multicolumn{6}{|c|}{ Sells } \\
\hline $\begin{array}{l}\text { Price } \\
\text { Volume } \\
\text { \#Trades }\end{array}$ & $\begin{array}{l}2.73 \\
4020.6 \\
1.19\end{array}$ & $\begin{array}{l}21,571 \\
21,571 \\
21,571\end{array}$ & $\begin{array}{l}2.45 \\
4837.1 \\
1.21\end{array}$ & $\begin{array}{l}25,728 \\
25,728 \\
25,728\end{array}$ & $\begin{array}{l}2.58 \\
4464.7 \\
1.20\end{array}$ & $\begin{array}{l}47,299 \\
47,299 \\
47,299\end{array}$ \\
\hline \multicolumn{3}{|l|}{ Others } & \multicolumn{2}{|c|}{ Buys } & & \\
\hline $\begin{array}{l}\text { Price } \\
\text { Volume } \\
\text { \#Trades }\end{array}$ & $\begin{array}{l}1.56 \\
2177.2 \\
1.14\end{array}$ & $\begin{array}{l}4,036 \\
4,036 \\
4,036\end{array}$ & $\begin{array}{l}1.45 \\
2256.1 \\
1.24\end{array}$ & $\begin{array}{l}5,146 \\
5,146 \\
5,146\end{array}$ & $\begin{array}{l}1.50 \\
2221.4 \\
1.19\end{array}$ & $\begin{array}{l}9,182 \\
9,182 \\
9,182\end{array}$ \\
\hline \#Trades & \multicolumn{6}{|c|}{ Sells } \\
\hline $\begin{array}{l}\text { Price } \\
\text { Volume } \\
\text { \#Trades }\end{array}$ & $\begin{array}{l}1.47 \\
3204.9 \\
1.41\end{array}$ & $\begin{array}{l}41,394 \\
41,394 \\
41,394\end{array}$ & $\begin{array}{l}1.34 \\
3931.1 \\
1.43\end{array}$ & $\begin{array}{l}46,582 \\
46,582 \\
46,582\end{array}$ & $\begin{array}{l}1.40 \\
3589.4 \\
1.42\end{array}$ & $\begin{array}{l}87,976 \\
87,976 \\
87,976\end{array}$ \\
\hline \multicolumn{3}{|l|}{ Total } & \multicolumn{2}{|c|}{ Buys } & & \\
\hline $\begin{array}{l}\text { Price } \\
\text { Volume } \\
\text { \#Trades }\end{array}$ & $\begin{array}{l}2.34 \\
3964.0 \\
1.50\end{array}$ & $\begin{array}{l}81,849 \\
81,849 \\
81,849\end{array}$ & $\begin{array}{l}2.25 \\
5057.8 \\
1.55\end{array}$ & $\begin{array}{l}101,456 \\
101,456 \\
101,456\end{array}$ & $\begin{array}{l}2.29 \\
4569.4 \\
1.53\end{array}$ & $\begin{array}{l}183,305 \\
183,305 \\
183,305\end{array}$ \\
\hline \#Trades & \multicolumn{6}{|c|}{ Sells } \\
\hline $\begin{array}{l}\text { Price } \\
\text { Volume } \\
\text { \#Trades }\end{array}$ & $\begin{array}{l}2.49 \\
4045.7 \\
1.48\end{array}$ & $\begin{array}{l}87,034 \\
87,034 \\
87,034\end{array}$ & $\begin{array}{l}2.36 \\
5132.8 \\
1.57\end{array}$ & $\begin{array}{l}98,070 \\
98,070 \\
98,070\end{array}$ & $\begin{array}{l}2.42 \\
4621.7 \\
1.53\end{array}$ & $\begin{array}{l}185,104 \\
185,104 \\
185,104\end{array}$ \\
\hline
\end{tabular}

Composition of transaction data. The average traded price, the average volume and the average number of trades re separately reported for long and short leverage certificates and market, limit and other orders. Moreover, data is divided into buys and sells. The traded price is calculated as the volume weighted averaged price for the time period before a specific quote. Volume values and the number of trades are aggregated over the time period before the quote. $N$ denotes the number of observations, for which a respective trade was recorded beforehand. 
Table 3: Absolute and Relative Premiums

\begin{tabular}{|c|c|c|c|c|c|c|c|}
\hline & \multirow[b]{2}{*}{ Measure } & \multicolumn{5}{|c|}{ Quintiles of Moneyness at Quote $M a Q$} & \multirow[b]{2}{*}{ Total } \\
\hline & & 1 st & 2nd & 3rd & 4 th & 5 th & \\
\hline \multirow{3}{*}{ Long } & $A P$ & 0.1822 & 0.1736 & 0.1696 & 0.1684 & 0.1705 & 0.1724 \\
\hline & $R P$ & 0.1589 & 0.0613 & 0.0390 & 0.0268 & 0.0165 & 0.0552 \\
\hline & $N$ & 441,266 & 481,663 & 504,715 & 537,288 & 652,124 & $2,617,056$ \\
\hline \multirow{3}{*}{ Short } & $A P$ & 0.1684 & 0.1537 & 0.1451 & 0.1421 & 0.1426 & 0.1516 \\
\hline & $R P$ & 0.1664 & 0.0556 & 0.0339 & 0.0228 & 0.0144 & 0.0656 \\
\hline & $N$ & 499,440 & 459,035 & 435,988 & 403,411 & 288,573 & $2,086,447$ \\
\hline \multirow{3}{*}{ Total } & $A P$ & 0.1749 & 0.1639 & 0.1583 & 0.1571 & 0.1619 & 0.1632 \\
\hline & $R P$ & 0.1629 & 0.0585 & 0.0367 & 0.0251 & 0.0158 & 0.0598 \\
\hline & $N$ & 940,706 & 940,698 & 940,703 & 940,699 & 940,697 & $4,703,503$ \\
\hline
\end{tabular}

Average premiums, i.e., relative and absolute differences between retail prices (arithmetic mean of ask and bid price) Average premiums, i.e., relative and absolute differences between retail prices (arithmetic mean of ask and bid price)
and model values. $N$ denotes the number of observations. Relative $R P$ and absolute $A P$ markups are reported for and model values. $N$ denotes the number of observations. Relative $R P$ and absolute $A P$ markups are repor
long and short leverage certificates separately and also for different quintiles of moneyness at quote $M a Q$. 
Table 4: Regression Results for Absolute Markups

\begin{tabular}{|c|c|c|c|c|c|c|}
\hline & & \multicolumn{5}{|c|}{ Quintiles of Moneyness at Quote $M a Q$} \\
\hline & & 1st Q- $M a Q$ & 2nd Q-MaQ & 3rd Q- MaQ & 4th Q-MaQ & 5th $\mathrm{Q}-M a Q$ \\
\hline & rel.TtM & $0.0199^{* * *}$ & $0.0256^{* * *}$ & $0.0256^{* * *}$ & $0.0245^{* * *}$ & $0.0277^{* * *}$ \\
\hline$\vec{\emptyset}$ & $\begin{array}{l}930-1600 \\
1700-1950\end{array}$ & $\begin{array}{l}0.0012^{* *} \\
-0.0108^{* * *}\end{array}$ & $\begin{array}{l}0.0012^{*} \\
-0.0119^{* * *}\end{array}$ & $\begin{array}{l}-0.0008 \\
-0.0148^{* * *}\end{array}$ & $\begin{array}{l}-0.0002 \\
-0.0127^{* * *}\end{array}$ & $\begin{array}{l}0.0013 \\
-0.0083\end{array}$ \\
\hline 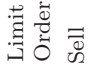 & $\begin{array}{l}930-1600 \\
1700-1950\end{array}$ & $\begin{array}{l}-0.0021^{* * *} \\
0.0092^{* * *}\end{array}$ & $\begin{array}{l}-0.0023^{* * *} \\
0.0136^{* * *}\end{array}$ & $\begin{array}{l}-0.0028^{* *} \\
0.0064^{* *}\end{array}$ & $\begin{array}{l}0.0011 \\
0.0047\end{array}$ & $\begin{array}{l}-0.0016 \\
0.0162^{* * *}\end{array}$ \\
\hline \multirow{2}{*}{ 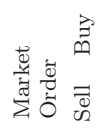 } & $\begin{array}{l}930-1600 \\
1700-1950\end{array}$ & $\begin{array}{l}0.0000 \\
-0.0068^{* * *}\end{array}$ & $\begin{array}{l}0.0026^{* * *} \\
-0.0026\end{array}$ & $\begin{array}{l}0.0014 \\
-0.0081^{* *}\end{array}$ & $\begin{array}{l}-0.0004 \\
0.0021\end{array}$ & $\begin{array}{l}-0.0034 \\
0.0016\end{array}$ \\
\hline & $\begin{array}{l}930-1600 \\
1700-1950\end{array}$ & $\begin{array}{l}-0.0007 \\
0.0051^{* * *}\end{array}$ & $\begin{array}{l}-0.0024^{* *} \\
0.0127^{* * *}\end{array}$ & $\begin{array}{l}-0.0031^{* *} \\
0.0058\end{array}$ & $\begin{array}{l}-0.0067^{* * *} \\
0.0033\end{array}$ & $\begin{array}{l}-0.0079^{* *} \\
0.0054\end{array}$ \\
\hline 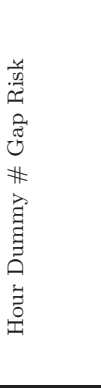 & $\begin{array}{l}\text { Hour } 930 \\
\text { Hour } 1000 \\
\text { Hour } 1100 \\
\text { Hour } 1200 \\
\text { Hour } 1300 \\
\text { Hour } 1400 \\
\text { Hour } 1500 \\
\text { Hour } 1600 \\
\text { Hour } 1700 \\
\text { Hour } 1730 \\
\text { Hour } 1800 \\
\text { Hour } 1900 \\
\text { Hour } 1930 \\
\text { Hour } 1950\end{array}$ & $\begin{array}{l}2.5893 \\
2.5391^{* * *} \\
2.5638^{* * *} \\
2.4555^{* * *} \\
2.5443^{* * *} \\
2.5554^{* * *} \\
2.3971^{* * *} \\
2.2810^{* * *} \\
0.5304^{* * *} \\
2.7562^{* * *} \\
3.7384^{* * *} \\
3.9748^{* * *} \\
3.7396^{* * *} \\
4.2621^{* * *}\end{array}$ & $\begin{array}{l}9.2981^{* * *} \\
2.5065^{* * *} \\
2.2424^{* * *} \\
2.2668^{* * *} \\
2.3251^{* * *} \\
2.2275^{* * *} \\
2.3312^{* * *} \\
2.3981^{* * *} \\
1.4561^{* * *} \\
2.4202^{* * *} \\
2.2458^{* * *} \\
2.3169^{* * *} \\
2.3287^{* * *} \\
2.5269^{* * *}\end{array}$ & $\begin{array}{l}4.7721^{*} \\
2.4293^{* * *} \\
2.003^{* * *} \\
2.303^{* * *} \\
2.2724^{* * *} \\
2.2167^{* * *} \\
2.3511^{* * *} \\
2.4892^{* * *} \\
1.896^{* * *} \\
2.4098^{* * *} \\
1.9232^{* * *} \\
1.9469^{* * *} \\
2.0258^{* * *} \\
2.1725^{* * *}\end{array}$ & $\begin{array}{l}2.0329 \\
1.4370^{* * *} \\
1.3387^{* * *} \\
1.4938^{* * *} \\
1.4238^{* * *} \\
1.3756^{* * *} \\
1.6010^{* * *} \\
1.6499^{* * *} \\
2.8605^{* * *} \\
2.2791^{* * *} \\
1.7847^{* * *} \\
1.6882^{* * *} \\
1.8785^{* * *} \\
2.0190^{* * *}\end{array}$ & $\begin{array}{l}-3.0835^{* * *} \\
-1.1016^{* * *} \\
-0.9999^{* * *} \\
-0.9233^{* * *} \\
-1.0451^{* * *} \\
-0.9518^{* * *} \\
-0.6583^{* * *} \\
-0.8351^{* * *} \\
0.5184^{* * *} \\
0.1811 \\
-0.3457^{* * *} \\
-0.3572^{* * *} \\
-0.5199^{* * *} \\
-0.5383^{* * *}\end{array}$ \\
\hline \multirow[t]{3}{*}{ 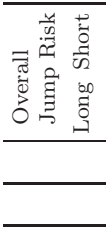 } & $\begin{array}{l}930-1600 \\
1700-1950 \\
930-1600 \\
1700-1950\end{array}$ & $\begin{array}{l}-0.2889^{* * *} \\
-0.0734^{* *} \\
0.7659^{* * *} \\
0.0571\end{array}$ & $\begin{array}{l}-0.6856^{* * *} \\
-0.3447^{* * *} \\
0.9905^{* * *} \\
0.6193^{* * *}\end{array}$ & $\begin{array}{l}-0.8148^{* * *} \\
-0.4545^{* * *} \\
1.0490^{* * *} \\
0.7405^{* * *}\end{array}$ & $\begin{array}{l}-0.9280^{* * *} \\
-0.9186^{* * *} \\
1.1513^{* * *} \\
0.5873^{* * *}\end{array}$ & $\begin{array}{l}-1.0914^{* * *} \\
-1.3527^{* * *} \\
1.351^{* * *} \\
0.6926^{* * *}\end{array}$ \\
\hline & Spread & $1.6070^{* * *}$ & $2.4778^{* * *}$ & $2.1114^{* * *}$ & $3.0674^{* * *}$ & $1.8890^{* * *}$ \\
\hline & Long Dummy & $0.0021^{* * *}$ & $0.0032^{* * *}$ & $0.008^{* * *}$ & $0.0110^{* * *}$ & $0.0034^{* * *}$ \\
\hline \multirow[t]{4}{*}{$\begin{array}{l}\text { na } \\
0 \\
0 \\
0 \\
0 \\
0\end{array}$} & $\begin{array}{l}\text { Issuer Dummy } \\
\text { Quarter Dummy } \\
\text { Quintiles } T_{\text {Initial }} \\
\text { Friday Dummy } \\
\text { Intraday DAX Return }\end{array}$ & $\begin{array}{l}\text { yes } \\
\text { yes } \\
\text { yes } \\
\text { yes } \\
\text { yes }\end{array}$ & $\begin{array}{l}\text { yes } \\
\text { yes } \\
\text { yes } \\
\text { yes } \\
\text { yes }\end{array}$ & $\begin{array}{l}\text { yes } \\
\text { yes } \\
\text { yes } \\
\text { yes } \\
\text { yes }\end{array}$ & $\begin{array}{l}\text { yes } \\
\text { yes } \\
\text { yes } \\
\text { yes } \\
\text { yes }\end{array}$ & $\begin{array}{l}\text { yes } \\
\text { yes } \\
\text { yes } \\
\text { yes } \\
\text { yes }\end{array}$ \\
\hline & Constant & $0.1605^{* * *}$ & $0.1018^{* * *}$ & $0.0888^{* * *}$ & $0.0535^{* * *}$ & $0.1103^{* * *}$ \\
\hline & $R^{2}$ & 14.82 & 20.03 & 26.01 & 25.59 & 24.88 \\
\hline & $N$ & 809,724 & 814,898 & 813,002 & 810,786 & 807,960 \\
\hline
\end{tabular}

Results of markup regression 19 for absolute premiums. For the estimation is used a 2SLS approach where the spread is instrumented via the average spread over all products of the prior day and the first difference of the ratio of the spread of the most similar product and the average spread of the same day. Regressors are the relative time to maturity rel. for long and short certificates and for two parts of the day, the instrumented spread and a dummy for long leverage certificates. As controls are used dummies for the issuer, quarters and Fridays, initial time to maturity $T_{\text {t }}$, is conducted separately on subgroups of quotes formed by quintiles of moneyness at quote Q-MaQ. N denotes the number of observations. Significance at the $5 \%$ level is indicated with $*$, at the $1 \%$ level with ** and at the $0.1 \%$ level with ***. $t$-statistics are estimated using heteroskedasticity robust standard errors (White, 1980 ). 


\section{Figures}

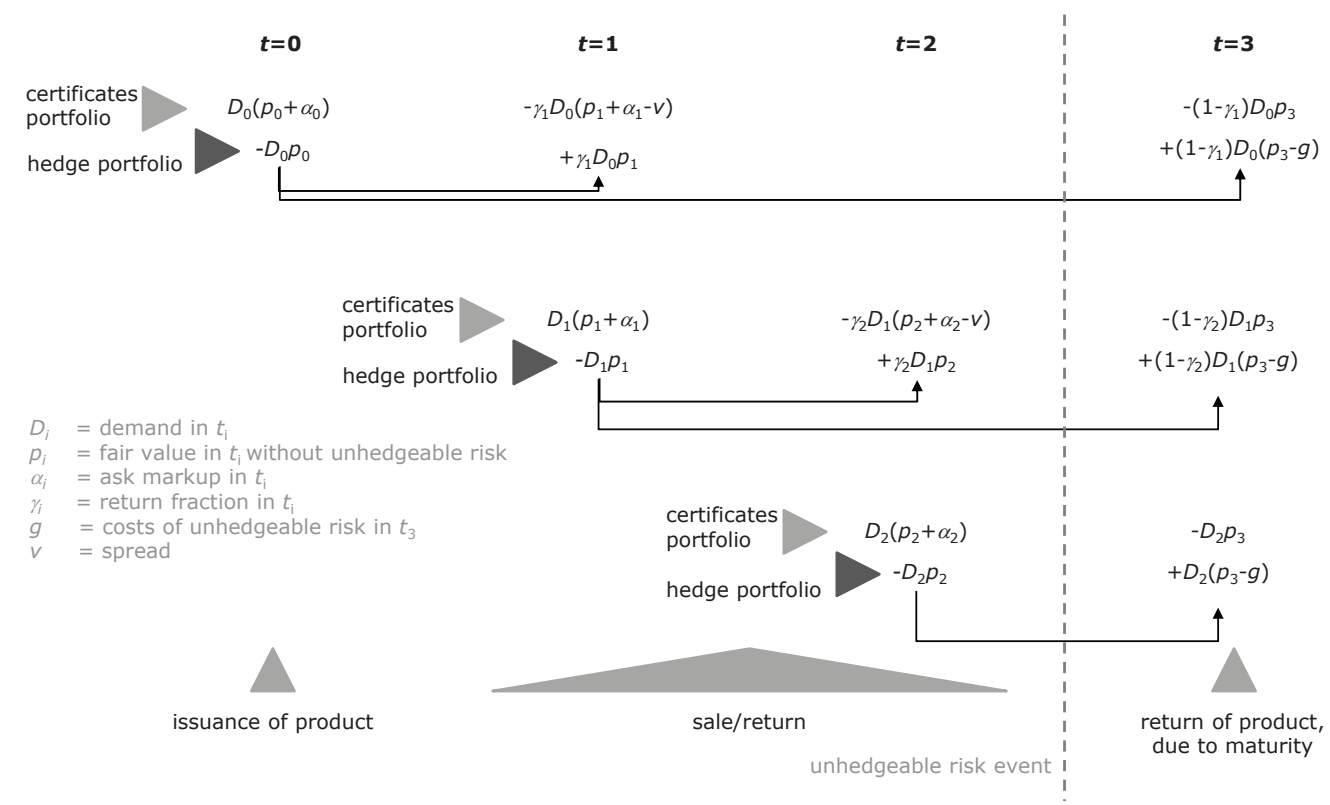

Figure 1: General model structure and resulting cash flows. The model consists of 4 discrete points in time $t_{i}=i, i=0,1,2,3$. The product is issued in $t_{0}$ and becomes due in $t_{3}$. At issuance, the market maker sets the fair price $p_{0}$ plus an ask markup $\alpha_{0}$. At maturity, he sets a bid price that equals the fair value $p_{i}$, i.e. the pay-off of the certificate. During the life time of the certificate he is willing to sell and rebuy certificates at ask and bid prices equal to the fair value $p_{i}$ in $t_{i}$ plus ask and bid markups $\alpha_{i}$ and $\alpha_{i}-v$, respectively, where $v$ denotes the bid-ask spread. The issuer immediately hedges the outstanding position at the fair value $p_{i} . D_{i}$ denotes the market demand function and $\gamma_{i}$ the immediate or accordingly $1-\gamma_{i}$ the return fraction in $t_{3}$. 

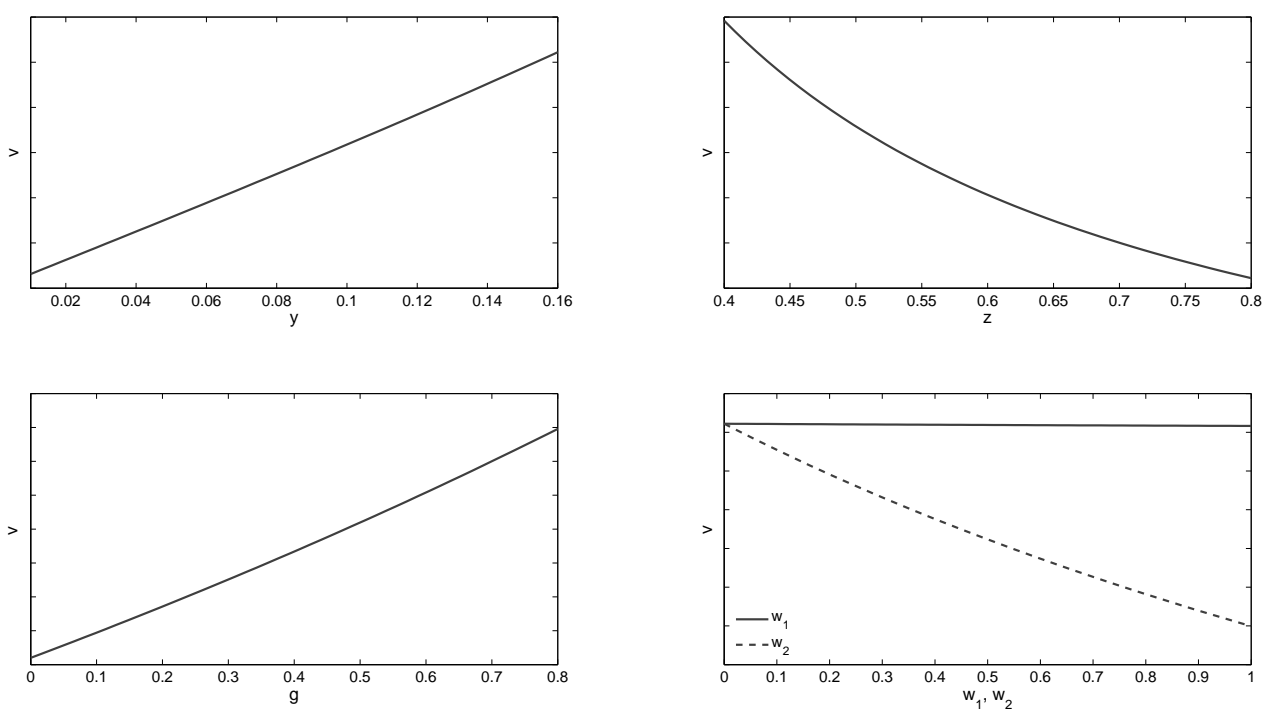

Figure 2: Comparative statics of the spread according to the markup and spread sensitivities $y$ and $z$, the opportunity costs of unhedgeable risk $g$ and exogenous demand shocks $w_{i}$. As fixed variable values are used $x=1, w_{i}=0, z=0.8, y=z / 5$ and $g=0.01$. 


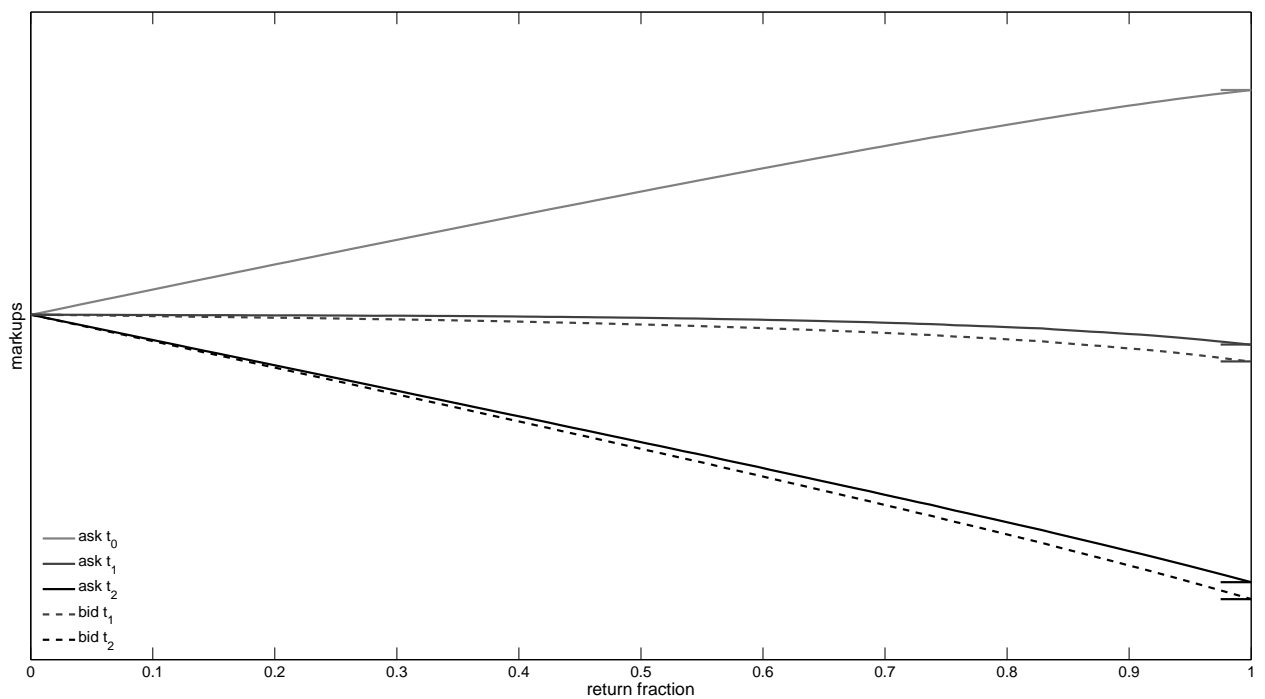

Figure 3: Optimal markups for different return fractions $\gamma_{i}$. For fractions equal to zero solutions are given by the special case in Chapter 2.3.1. For fractions equal to unity solutions are given by the special case in Chapter 2.3.2. As fixed variable values are used $x=1$, $w_{i}=0, z=0.8, y=z / 5$ and $g=0.01$ 

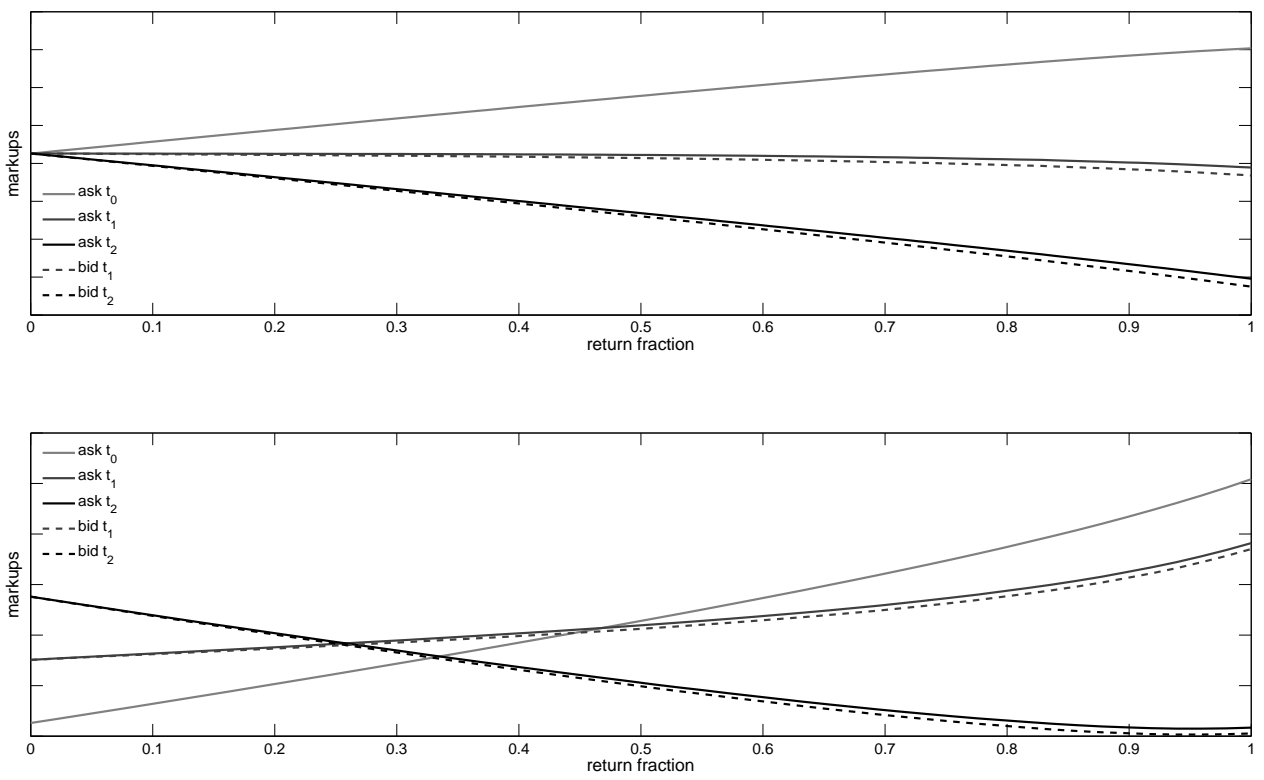

Figure 4: Optimal markups for different return fractions $\gamma_{i}$ with and without demand shifts. The upper Figure is identical to Figure 3 with exogenous demand shifts $w_{i}=0$. The lower Figure gives optimal markups for the same values of variable as the upper but with exogenous demand shocks $w_{1}=0.2$ and $w_{1}=0.4$. As fixed variable values are used $x=1, z=0.8, y=z / 5$ and $g=0.01$. 


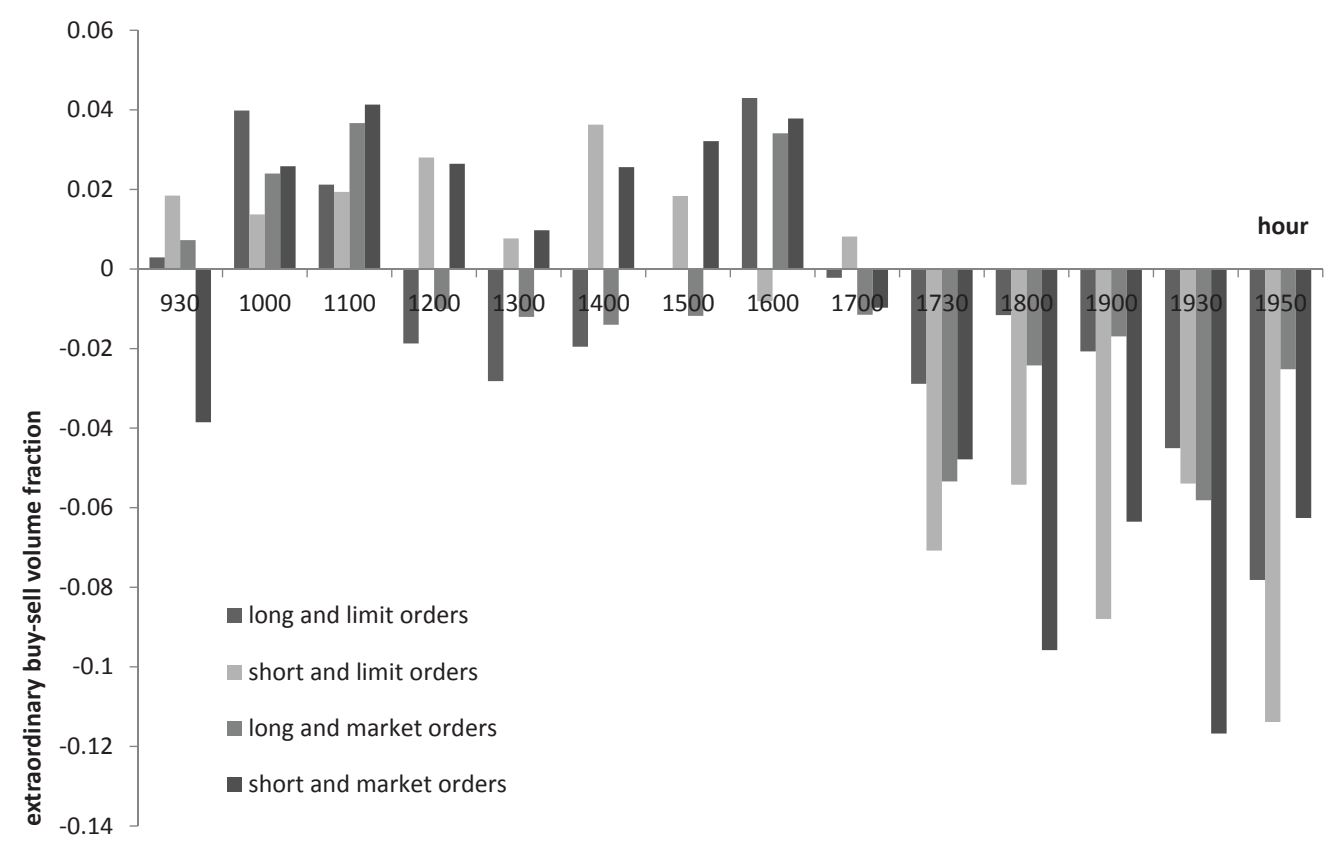

Figure 5: Extraordinary average buy-sell-fractions over the day, i.e. the difference between the mean hourly and the overall daily Ferage buy-sell volume fraction. Data is reported separately for limit and market orders and short and long certificates.
averate 